\title{
DO NOT PANIC: HOW TO AVOID INEFFICIENT RUSHES USING MULTI-STAGE AUCTIONS
}

\section{Ángel Hernando-Veciana Fabio Michelucci}

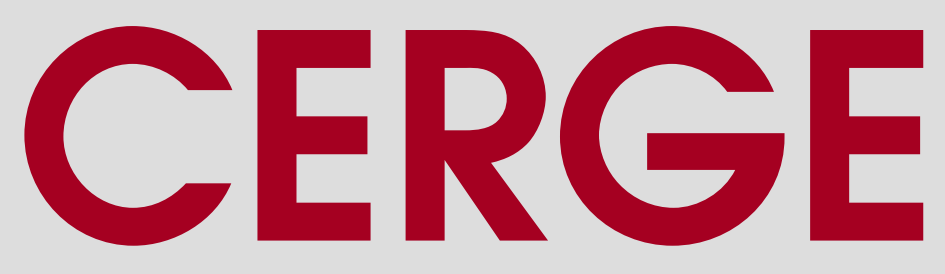




\section{Working Paper Series 489 (ISSN 1211-3298)}

\section{Do Not Panic: \\ How to Avoid Inefficient Rushes Using Multi-Stage Auctions}

Ángel Hernando-Veciana

Fabio Michelucci

\section{CERGE-EI}

Prague, August 2013 
ISBN 978-80-7343-293-5 (Univerzita Karlova. Centrum pro ekonomický výzkum a doktorské studium)

ISBN 978-80-7344-285-9 (Národohospodářský ústav AV ČR, v.v.i.) 


\title{
Do Not Panic: How to Avoid Inefficient Rushes Using Multi-Stage Auctions*
}

\author{
Ángel Hernando-Veciana ${ }^{\dagger}$ \\ Universidad Carlos III de Madrid
}

\author{
Fabio Michelucci ${ }^{\ddagger}$ \\ CERGE-EI
}

\begin{abstract}
We show that open ascending auctions are prone to inefficient rushes, i.e. all bidders quitting at the same price, in market environments such as privatizations, takeover contests, and procurement auctions. Rushes arise when an incumbent with better information about a common value component of the asset for sale quits, and his exit reveals negative information. Rushes can be avoided, and expected social surplus maximized, by reducing the disclosure of information with the use of a multi-stage auction. Thus, our results point out to an important limitation of market mechanisms that provide immediate information disclosure to all agents in a market.
\end{abstract}

JEL Classification Numbers: D44, D82. Keywords: efficiency, auctions, mechanism design, two stage mechanisms.

${ }^{*}$ We would like to thank the participants of the First ESEI Workshop on Market Design (http://www.esei.ch/conferences/1st-workshop) for useful comments. In particular, Paul Klemperer for encouraging us to explore and discuss the use of non standard tie breaking rules. We also would like thank Jakub Steiner and Jan Zapal for their detailed comments on the manuscript. Ángel Hernando-Veciana acknowledges the financial support of the Spanish Ministry of Economics and Competitiveness through grant ECO2012-38863.

${ }^{\dagger}$ Department of Economics. Universidad Carlos III de Madrid. c/ Madrid, 126. 28903 Getafe (Madrid) SPAIN. Email: angel.hernando@uc3m.es URL: http://www.eco.uc3m.es/ahernando/

${ }^{\ddagger}$ Fabio Michelucci, CERGE-EI, P.O. Box 882 Politickych veznu 711121 Praha 1 Czech Republic. Email: fabio.michelucci@cerge-ei.cz. CERGE-EI is a joint workplace of the Center for Economic Research and Graduate Education, Charles University, and the Economics Institute of the Academy of Sciences of the Czech Republic. 


\begin{abstract}
Ukazujeme, že otevřené aukce se vzestupnou cenou jsou náchylné k neefektivním návalüm (tj. simultánnímu odchodu všech aktivních účastníkủ při stejné ceně) v tržních prostředích jako jsou privatizace, firemních akvizice pomocí soutěže, a aukcí při zadávní veřejných zakázek. $\mathrm{K}$ návalüm dochází v situaci kdy současný držitel aktiva, který má lepší informace o společné části hodnoty aktíva na prodej než ostatní účastníci, opustí aukci, a tento odchod odhalí negativní informace ostatním účastníküm. Návaly mohou být eliminovány, a očekávaná sociální nadhodnota zvýšena, snížením zveřejňování informací s použitím vícestupňového aukce. Naše výsledky tedy poukazují na dủležité omezení tržních mechanismú, které poskytují okamžité informace všem agentủm na trhu.
\end{abstract}




\section{Introduction}

The conventional wisdom suggests that market mechanisms that aggregate more information are more efficient, and consequently, information should be disclosed as soon as it becomes available. A drawback, however, is that information disclosure may lead to a rush: ${ }^{1}$

"Bankers said there had been a rush among wealthy individuals and asset managers to dump their gold holdings since Ben Bernanke, Federal Reserve chairman, last week set out for the first time a framework for the US central bank to exit its stimulus programme known as quantitative easing."

We illustrate this effect in an open ascending auction: inefficient rushes arise due to the immediate disclosure, to all active bidders, of the prices at which other bidders quit. We show how hiding some of this information may increase efficiency. Our analysis also challenges a common view in the theoretical literature on auctions, going back to Vickrey (1961), that emphasizes that under general circumstances the open ascending auction is the most efficient auction and that it does strictly better than the other standard auctions. This is the theoretical basis for the widespread support of the use of open ascending auctions in privatizations.

We provide two main results in a general setting with private and common value components in which the latter are privately known by one bidder. First, we show that the open ascending auction is prone to rushes, i.e. all bidders quitting simultaneously, which undermine its efficiency under standard tie breaking rules. We also identify particular conditions under which the open ascending auction is the least efficient of the standard auctions. Second, we show that the maximum expected social surplus can be achieved with a multi-stage auction, which is commonly used in privatizations. ${ }^{2}$ We also discuss alternative solutions to resolve rushes, such as the use of non-standard tie breaking rules, and argue that all the alternatives suffer from several problems. Paradoxically, our results also suggest that immediate information disclosure to all agents in a market may compromise the final amount of information unveiled. This is because rushes may preclude information aggregation.

\footnotetext{
${ }^{1}$ Financial Times, 26/06/2013, http://www.ft.com/intl/cms/s/0/9aac9378-de3f-11e2-9b47-00144feab7de.html\# axzz2bqSiqPQW

${ }^{2}$ For instance, ENI's privatization, see Caffarelli (1998) and Perry, Wolfstetter, and Zamir (2000), Telebras' privatization, see Dutra and Menezes (2002), and 2007 Nigerian $800 \mathrm{MHz}$ auction, see Nigerian-Communications-Commission (2007).
} 
We illustrate our main results with a motivating example: franchise bidding for a privatized service previously operated by an incumbent. The incumbent has private information about the demand for the service. Typically, the incumbent has lower setup costs whereas the other bidders, the entrants, may have lower marginal costs. Thus, the first best allocates the good to the incumbent when the demand for the service is small, and to the entrant with largest value (lowest marginal cost), otherwise. However, as it is well known, ${ }^{3}$ this allocation is not implementable. ${ }^{4}$

More generally, our model captures situations in which one bidder has insider information about a common value component of the bidders' valuations. Another example is the sale of a company where the common value is the stand alone value of assets, and the private values are bidders specific synergies. In this example, an insider information problem arises when a firm has close links with the management team, for example, a white knight in the case of a hostile take-over. In HernandoVeciana and Michelucci (2011), we show that also in these type of environments the first best may not be implementable.

We prove that the second best allocates the good to the entrant with largest value in cases in which the incumbent has higher value. In an open ascending auction, the incumbent finds it weakly dominant to stay active until the price reaches her value as in a private value setting. Hence, if one wishes to implement the second best allocation in an open ascending auction with an equilibrium in non weakly dominated strategies, it must be the case that in order to outbid the incumbent entrants remain active at prices at which they will make a loss if they win. This is actually what happens in equilibrium. The consequence is that rushes arise after the incumbent quits, which explains the inefficiencies of our first main result because standard tie breaking rules do not guarantee that the good is allocated to the entrant with largest value. Quite remarkably, rushes may arise with a probability arbitrarily close to one.

Our multi-stage auction starts with a sealed bid phase followed by a second stage in which the first stage bids and identities of all the bidders but the two highest, the top bidders, are made public and the top bidders are allowed to revise their bids upwards to their final bids. The top bidder that submits the highest final bid wins the auction at a price equal to the final bid of the other top bidder. This auction generalizes the desirable properties of the second price auction (see Hernando-Veciana

\footnotetext{
${ }^{3}$ See for instance, Maskin (1992).

${ }^{4}$ In this paper, we say that an allocation is implementable when it is the equilibrium outcome of some mechanism. Note that this differs from the notion of full implementation that requires the allocation to be the unique equilibrium outcome of some mechanism.
} 
and Michelucci (2011)) allowing for the disclosure of the bidders' private information without affecting their bidding incentives. Our second main result arises because the first stage bids commit each entrant to a different minimum price. Hence, entrants do not tie if they stick to their respective minimum price.

Our results complement the analyses of Klemperer (1998), Perry, Wolfstetter, and Zamir (2000), Klemperer (2002), Dutra and Menezes (2002) and Levin and Ye (2008), Ye (2007), and Boone and Goeree (2009) that support the use of multi-stage auctions rather than open ascending auctions in privatizations. Perry, Wolfstetter, and Zamir (2000) study the same multi-stage auction as us, but restrict attention to a setting where rushes do not arise in equilibrium. All the other papers look at either Anglo-Dutch hybrid auctions or auctions including a stage with non-binding indicative bidding. The main difference of this study as compared with all these papers is that they compare the auction formats on the basis of expected revenue only.

The inefficiencies in our setting are due to rushes, which only arise when the first best is not implementable. ${ }^{5}$ Hernando-Veciana and Michelucci (2011) also study a setting in which the first best is not implementable but they do not have inefficient rushes because they restrict attention to the case of two bidders. Bulow and Klemperer (1994) have pointed out a symmetric effect in open descending auctions: one bidder seizing one unit prompts bidders with different willingnesses to pay to simultaneously demand one unit at the same price at which the first bidder has seized the first unit leading to a tie. Their effect, however, requires a descending auction, and multiunit sales and it is unrelated to the implementability of the first best.

The plan of the paper is as follows. We start by defining our theoretical setting, Section 2, and characterizing the second best, in Section 3. Section 4 analyses the open ascending auction. Section 5 identifies the conditions under which standard auctions outperform open ascending auctions, and Section 6 presents our multi-stage solution to rushes when such special conditions do not hold. Section 7 discusses alternative solutions, and finally, 8 concludes.

\section{The Model}

One unit of an indivisible good is put up for sale to $n+1$ bidders with quasilinear preferences in money. Bidder 1 , the incumbent, puts monetary value $\hat{v}\left(s_{1}\right)$ on getting the good and each Bidder $i$,

\footnotetext{
${ }^{5}$ The efficiency of the English auction when the first best is implementable has been studied by Maskin (1992), Krishna (2003), Dubra, Echenique, and Manelli (2009), and Birulin and Izmalkov (2011).
} 
$i \in\{2, \ldots, n+1\}$, with $n>1$, the entrants, puts monetary value $v\left(s_{i}, s_{1}\right)$, where $s_{i}$, denotes Bidder $i$ 's private information. We assume that all the signals are independent, $s_{1}$ follows a distribution $F_{1}$, density $f_{1}, s_{i}$ follows a distribution $F_{i}$, density $f_{i}, \forall i$, and all have support normalized to be $[0,1]{ }^{6}$

We assume that both $\hat{v}$ and $v$ are increasing, strictly in the case of $\hat{v}$ and the first argument of $v$. To simplify the exposition, we assume that the functions $v$ and $\hat{v}$ are continuous although our results do not hinge on this assumption. Throughout this paper, the equilibrium concept is perfect Bayesian equilibrium in non-weakly dominated strategies.

The framework above provides a model that is rich enough to fit the market environments described in the introduction, and that at the same time is tractable. In particular, assuming that the incumbent knows her valuation allows to restrict attention to equilibria of the open ascending auction in non weakly dominated strategies, which has the advantage of getting rid of the multiplicity of equilibria typical of this format. Even more importantly, it allows to characterize the (second best) efficient allocation, and thus to able to carry out an analysis of the effect of rushes from the point of view of efficiency. The characterization of the second best in a general framework is a long standing open question in the auction literature, which is beyond the scope of this paper.

\section{Second Best Allocations}

In this section, we characterize the second best allocation. We start introducing some definitions.

An allocation is a measurable function $p$ from the set of types $[0,1]^{n+1}$ into the $(n+1)$-dimensional simplex $\Delta(n+1)$ such that $p_{i}(s)$ denotes the probability of allocating the good to Bidder $i$ when the vector of types is $s .^{7}$ We say that an allocation $p$ is monotone if $p_{j}$ is increasing in $s_{j}, j \in\{1, \ldots, n+1\}$.

We are interested in the set of implementable allocations, which are the allocations that are the equilibrium outcome of a mechanism. ${ }^{8}$ We say that an allocation is second best if it maximizes the

\footnotetext{
${ }^{6}$ In all the paper we adopt the convention to refer to a generic entrant as "he" and to the incumbent as "she".

${ }^{7}$ Note that we do not allow for the seller keeping the object. This is a common assumption in the models that study the efficiency of the open ascending auctions, e.g. Krishna (2003). For an analysis of the role of not allocating on efficiency, see Hernando-Veciana and Michelucci (2013).

${ }^{8}$ An allocation $p$ is implementable if a truthful equilibrium exists in a direct mechanism $(p, x)$. A direct mechanism is a pair of measurable functions $(p, x)$, where $p$ is an allocation and $x:[0,1]^{n+1} \rightarrow \Delta(n+1)$ a payment function. A direct mechanism $(p, x)$ defines a game in which each bidder announces a type, and $p_{i}(s)$ denotes the probability that $i$ gets the good and $x_{i}(s)$ her payment to the auctioneer when the vector of announced types is $s \in[0,1]^{n+1}$. A truthful equilibrium of a direct mechanism is an equilibrium in which all the bidders announce their true types. By the revelation principle, there is no loss of generality in restricting to truthful equilibria of direct mechanisms.
} 
expected social surplus: ${ }^{9}$

$$
\int_{[0,1]^{n}} \int_{[0,1]}\left(p_{1}(s) \hat{v}\left(s_{1}\right)+\sum_{i} p_{i}(s) v\left(s_{i}, s_{1}\right)\right) d F_{1}\left(s_{1}\right) d F_{-1}\left(s_{-1}\right),
$$

subject to implementability, where $F_{-1}\left(s_{-1}\right)$ stands for $\prod_{i=2}^{n+1} F_{i}\left(s_{i}\right)$.

We shall use an auxiliary function $\phi:[0,1] \rightarrow[0,1]$ that associates to any $s_{i} \in[0,1]$ the solution of:

$$
\max _{\tilde{s}_{1} \in[0,1]} \int_{0}^{\tilde{s}_{1}}\left(v\left(s_{i}, s_{1}\right)-\hat{v}\left(s_{1}\right)\right) d F_{1}\left(s_{1}\right) .
$$

Since $v$ is strictly increasing in $s_{i}$, the above objective function is strictly supermodular in $\left(s_{i}, \tilde{s}_{1}\right)$ and hence $\phi$ is weakly increasing in $s_{i}$ (strictly when $\phi\left(s_{i}\right) \in(0,1)$ ). Besides, $\phi$ is uniquely defined for almost all $s_{i} \in[0,1] .^{10,11}$

To interpret $\phi$, add $\int_{0}^{1} \hat{v}\left(s_{1}\right) d F_{1}\left(s_{1}\right)$ to Equation (2) and take expectations with respect to $s_{i}$ assuming that $s_{i}$ follows the distribution of the maximum of the entrants' types $s_{(1)} \equiv \max \left\{s_{2}, \ldots, s_{n+1}\right\}$. Thus, $\phi$ is also the unique (up to a set of measure zero) function $\tilde{\phi}:[0,1] \rightarrow[0,1]$ that maximizes:

$$
\int_{0}^{1}\left(\int_{0}^{\tilde{\phi}\left(s_{(1)}\right)} v\left(s_{(1)}, s_{1}\right) d F_{1}\left(s_{1}\right)+\int_{\tilde{\phi}\left(s_{(1)}\right)}^{1} \hat{v}\left(s_{1}\right) d F_{1}\left(s_{1}\right)\right) d F_{(1)}\left(s_{(1)}\right)
$$

where $F_{(1)}\left(s_{(1)}\right)=\prod_{i=2}^{n+1} F_{i}\left(s_{(1)}\right)$.

The above expression is equal to the expected social surplus generated by an allocation that assigns the good to the entrant with highest type $s_{(1)}$ if $\tilde{\phi}\left(s_{(1)}\right) \geq s_{1}$ or otherwise to the incumbent. We refer to any allocation that satisfies these properties as the allocation associated to $\tilde{\phi}$. Let $\Phi$ be the set of the allocations $p$ for which a $\tilde{\phi}$ exists such that $p$ is associated to $\tilde{\phi}:[0,1] \rightarrow[0,1]$. Thus, the allocation associated to $\phi$ is the unique (up to a set of measure zero) allocation that maximizes the expected social surplus among the allocations in $\Phi$. Further:

Lemma 1. The allocation p that maximizes the expected social surplus, Equation (1), subject to:

$$
Q_{1}\left(s_{1}, p\right) \equiv \int_{[0,1]^{n}} p_{1}\left(s_{1}, s_{-1}\right) d F_{-1}\left(s_{-1}\right) \text { increasing in } s_{1}
$$

belongs to $\Phi$.

\footnotetext{
${ }^{9}$ Since we assume preferences quasilinear in money, second best efficiency is equivalent to Holmström and Myerson's (1983) concept of ex ante incentive efficiency.

${ }^{10}$ Since the objective function is strictly supermodular, the set of solutions is a correspondence strictly increasing in $s_{i}$, see for instance Amir (2005), and hence it is single valued almost everywhere in its domain.

${ }^{11}$ It is irrelevant for our analysis how we define $\phi$ in the case in which there are several solutions to the previous equation. As a convention, we take $\phi$ equal to the minimum solution.
} 
Proof. Note that the maximization in the lemma is equivalent to the following two stage maximization. First, one maximizes the expected social surplus, Equation (1), with respect to $p$ subject to the constraint $Q(., p)=\hat{Q}($.$) for an arbitrary increasing function \hat{Q}:[0,1] \rightarrow[0,1]$, and second, one maximizes with respect to $\hat{Q}($.) the resulting outcome of the first maximization subject to $\hat{Q}$ increasing. For any $\hat{Q}:[0,1] \rightarrow[0,1]$ increasing, the corresponding first stage maximization can be rewritten as follows:

$$
\begin{gathered}
\max _{p:[0,1]^{n+1} \rightarrow \Delta(n+1)} \int_{0}^{1} \hat{v}\left(s_{1}\right) \hat{Q}\left(s_{1}\right) d F_{1}\left(s_{1}\right)+\int_{[0,1]^{n+1}}\left(\sum_{i \neq 1} p_{i}(s) v\left(s_{i}, s_{1}\right)\right) d F_{1}\left(s_{1}\right) d F_{-1}\left(s_{-1}\right) \\
\text { s.t. } \int_{[0,1]^{n}} \sum_{i \neq 1} p_{i}(s) d F_{-1}\left(s_{-1}\right)=1-\hat{Q}\left(s_{1}\right) \forall s_{1} \in[0,1] .
\end{gathered}
$$

Since the objective function is a continuous function defined in a compact set it has a maximum if the feasible set is non empty. It is easy to see that this is the case. To characterize its maximum we leave aside the first term, which is constant in $p$, and write the Lagrangian associated:

$$
\begin{aligned}
\int_{[0,1]^{n+1}}\left(\sum_{i \neq 1} p_{i}(s) v\left(s_{i}, s_{1}\right)\right) d F_{1}\left(s_{1}\right) d F_{-1}\left(s_{-1}\right) & \\
& -\int_{0}^{1} \lambda\left(s_{1}\right)\left(\int_{[0,1]^{n}} \sum_{i \neq 1} p_{i}(s) d F_{-1}\left(s_{-1}\right)-\left(1-\hat{Q}\left(s_{1}\right)\right)\right) d F_{1}\left(s_{1}\right),
\end{aligned}
$$

where $\lambda:[0,1] \rightarrow \mathbb{R}$ is the Lagrange multiplier. Reorganizing the Lagrangian we get:

$$
\int_{[0,1]^{n+1}}\left(\sum_{i \neq 1} p_{i}(s)\left(v\left(s_{i}, s_{1}\right)-\lambda\left(s_{1}\right)\right)\right) d F_{1}\left(s_{1}\right) d F_{-1}\left(s_{-1}\right)+\int_{0}^{1} \lambda\left(s_{1}\right)\left(1-\hat{Q}\left(s_{1}\right)\right) d F_{1}\left(s_{1}\right) .
$$

For a given function $\lambda$, the allocation that maximizes the above problem is characterized almost everywhere by a function $\psi:[0,1] \rightarrow[0,1]$ implicitly defined by $v\left(\psi\left(s_{1}\right), s_{1}\right)=\lambda\left(s_{1}\right)$ if a solution to such equation exists, and by zero or one if $v\left(0, s_{1}\right)>\lambda\left(s_{1}\right)$ or $v\left(1, s_{1}\right)<\lambda\left(s_{1}\right)$, respectively. The good is allocated to the incumbent if $\psi\left(s_{1}\right)>s_{(1)}$ and otherwise to the entrant with highest type. The constraint of our problem requires that $F_{(1)}\left(\psi\left(s_{1}\right)\right)=\hat{Q}_{1}\left(s_{1}\right)$. Since $F$ and $\hat{Q}$ are increasing, so is $\psi$. This implies that the optimizers of our first stage maximization belong to $\Phi$, and so does the optimizers of the whole problem, as desired.

One can show by adapting Myerson's (1981) arguments that Equation (4) is a necessary condition for implementability. Furthermore, the allocation associated to $\phi$ is implementable because it is monotone. ${ }^{12}$ Hence, the next result is a corollary to Lemma 1.

\footnotetext{
${ }^{12}$ Monotonicity is equivalent to ex-post implementability, which implies Bayesian implementability. See Chung and
} 
Corollary 1. The second best allocations are equal to the allocation associated to $\phi$ almost everywhere.

A key fact that follows from the above characterization of the second best is that in the second best allocation it is never the case that an entrant who has not the highest ex-post value for the asset for sale gets the object. The reason why the second best, if it allocates to an entrant, is always able to select the one with highest value is that in the constrained maximization problem that we solved to determine the second best solution the only incentive compatibility constraint that was binding was the one for the incumbent. Below we exploit the mentioned fact to prove that open ascending auctions cannot implement the second best.

\section{The Open Ascending Auction}

We assume the model of the open ascending auction described by Krishna (2003). This auction model is a variation of the Japanese auction proposed by Milgrom and Weber (1982) in which the identity of the bidders is observable. This is a dynamic game in which bidders decide when to quit. The price starts at zero and increases continuously until one bidder quits. Then, the price stops increasing and the following algorithm is implemented. The identify of the bidders that last quit is made public. If all the bidders have already quit, the good is allocated with equal probability among the bidders that quit last at the current price. Otherwise, the bidders that have not quit yet can decide (independently and simultaneously) whether to quit. If some other bidders quit, we repeat the former algorithm. Otherwise, the price begins to increase continuously again until some other bidder quits. In this case, we repeat the former algorithm.

In this section we first provide conditions under which the second best allocation cannot be implemented with an open ascending auction. Second, we focus on a particular framework to illustrate the equilibrium of the open ascending auction when it does not implement the second best and discuss the potential efficiency losses.

Before providing the formal arguments for the two claims above, it is worthwhile to introduce a simple example to illustrate the type of environments we are looking at, and to provide the intuition for why rushes occur in those environments in equilibrium. We also use the example to give a simplified argument for the first claim.

Ely (2002). Alternatively, we provide a mechanism and an equilibrium that implements the allocation associated to $\phi$ in Section 6. 
Example 1. $\hat{v}\left(s_{1}\right)=s_{1}+1 / 2, v\left(s_{i}, s_{1}\right)=\frac{s_{i}}{3}+3 s_{1} F_{1}$ and $F_{i}, \forall i$ uniform.

The example models situations, such as the franchise bidding described in the Introduction, where an incumbent, Bidder 1, is ex-post more efficient (has higher value) than the entrants, Bidder $i$ 's, if her private information indicates a small market (low $s_{1}$ ), while entrants are more efficient, otherwise (high $s_{1}$ ). As a building up exercise focus on one entrant only. The equilibrium strategies are: $b_{1}\left(s_{1}\right)=s_{1}+\frac{1}{2}$, and $b_{i}\left(s_{i}\right)=\frac{3}{2}, \forall s_{i}$. Thus, in equilibrium, any type of the entrant outbids the incumbent. If the incumbent quits at $p<\frac{3}{4}-\frac{s_{i}}{6}$, outbidding her conveys "bad news" to the entrant, as it means that he wins the auction, but $p>\frac{s_{i}}{3}+3 s_{1}$. The reason why staying active as long as the incumbent is active is an equilibrium is that such expected losses are more than compensated by the expected profits from winning, when $p \geq \frac{3}{4}-\frac{s_{i}}{6}$. The resulting allocation is not first best efficient, but it is second best efficient. ${ }^{13}$ Suppose that we now add additional entrants that for simplicity are all ex-ante symmetric as stated in the example. The key observation is that the exit of the incumbent can provide negative information to all the bidders that are still active when the incumbent exits. In fact, if the incumbent quits at $p<\frac{7}{12}$ the information conveyed is so negative that any entrant still active (regardless of his type) will quit immediately. This means that in our environment entrants that hold different willingness to pay for the asset on sale quit at the same price after "bad news" is aggregated. But then since in a standard open auction the winner is randomly selected when a rush occurs, we have that the (second best) efficient allocation cannot be achieved because the latter never allocates to an entrant different from the one with highest type. While our main focus is on efficiency, notice that if one were also concerned with the ability of the market to aggregate information held by market participants, rushes would be detrimental even if they did not produce an inefficiency loss. This is so as the market after a rush occurs cannot distinguish between the different private information that the entrants the participated in the rush held. We do not stress this issue further as in our model the entrants private information is relevant only for him, and thus the loss in terms of information aggregation is present, but has no consequences.

To see why the open ascending auction cannot implement the second best in this example, suppose for the sake of contradiction that it does. Then, it is not possible that two or more bidders are active at $p>\frac{1}{2}$ as otherwise a rush would occur, which we argued is not compatible with the second best. In order to select to most efficient entrant to be the only one active at $p>\frac{1}{2}$, it must be that entrants quit according to some strictly increasing strategy such that even the highest possible type quits at some

\footnotetext{
${ }^{13}$ To determine the second best, Corollary 1 can be applied.
} 
$p \leq \frac{1}{2}$. However, if all entrants follow such strategy, any of them as a unilateral profitable deviation: to outbid all other entrants and stay active till the incumbent quits.

The proof in the subsection below proves the result in general following the same argument. The following subsection, instead, derives the equilibrium strategies for the open auction and thus shows that rushes indeed occur in equilibrium. Finally, Proposition 3 shows that rushes can happen with arbitrarily high probability.

\subsection{On the Impossibility of a Second Best Implementation}

It is easy to see that, as in private value auctions, the unique weakly dominant strategy for the incumbent is to remain in the auction until the price reaches her value $\hat{v}\left(s_{1}\right){ }^{14}$

Note that when the incumbent plays her weakly dominant strategy and quits at price $p$ an entrant can infer that the incumbent's type is equal to $\hat{v}^{-1}(p)$. An adaptation of the above argument implies that an entrant, after observing the incumbent dropping at $p$, finds it optimal to quit if and only if the current price is strictly greater than $v\left(s_{i}, \hat{v}^{-1}(p)\right)$, where $s_{i}$ denotes his type. Thus, an entrant of type $s_{i}<\rho\left(\hat{v}^{-1}(p)\right)$ quits immediately after the incumbent if the incumbent quits at price $p \in(\hat{v}(0), \hat{v}(1))$, where $\rho\left(s_{1}\right)$ is the solution in $s_{i}$ to $v\left(s_{i}, s_{1}\right)=\hat{v}\left(s_{1}\right)$ and either 0 or 1 if $v\left(0, s_{1}\right)>\hat{v}\left(s_{1}\right)$ or $v\left(1, s_{1}\right)<$ $\hat{v}\left(s_{1}\right)$, respectively. Further, an entrant of type $s_{i}$ in an information set in which all the other entrants have quit at a price $p \leq \hat{v}\left(\phi\left(s_{i}\right)\right)$ and the incumbent is still active finds it optimal to remain in the auction until price $\hat{v}\left(\phi\left(s_{i}\right)\right)$. To see why note that our entrant wins if and only if the incumbent's exits at $\hat{v}\left(s_{1}\right)$ less than $\tilde{p}$ and in this case pays the price at which the incumbent exited. Hence, the expected payoffs of our entrant when he bids $\tilde{p}$ are equal to:

$$
\int_{\hat{v}^{-1}(p)}^{\hat{v}^{-1}(\tilde{p})}\left(v\left(s_{i}, s_{1}\right)-\hat{v}\left(s_{1}\right)\right) \frac{d F_{1}\left(s_{1}\right)}{1-F_{1}\left(\hat{v}^{-1}(p)\right)},
$$

which is maximized at $\tilde{p}=\hat{v}(\phi(s))$ by definition of $\phi .{ }^{15}$

To simplify our arguments, we restrict attention to equilibria in which the entrants' strategy satisfy the two features discussed in the previous paragraph, though the restriction is unnecessary for our results.

\footnotetext{
${ }^{14}$ If the incumbent quits at a lower price than $\hat{v}\left(s_{1}\right)$, she misses the opportunity of winning at profitable prices and if she remains when the price goes above $\hat{v}\left(s_{1}\right)$, she risks winning when the price is higher than her value.

${ }^{15}$ To see why, notice that one can get the same maximand as in Equation $(2)$ multiplying by $1-F_{1}\left(\hat{v}^{-1}(p)\right)$ and adding $\int_{0}^{\hat{v}^{-1}(p)}\left(v\left(s_{i}, s_{1}\right)-\hat{v}\left(s_{1}\right)\right) d F_{1}\left(s_{1}\right)$ (both of which are constant with respect to $\left.\tilde{p}\right)$ after the change of variable $\tilde{p}=\hat{v}\left(\tilde{s}_{1}\right)$.
} 
For a given vector of types $\left(s_{1}, \ldots, s_{n+1}\right)$, we say that the first best allocates to the incumbent if $\hat{v}\left(s_{1}\right)>v\left(s_{(1)}, s_{1}\right)$, i.e. $s_{(1)}<\rho\left(s_{1}\right)$, and we say that the second best allocates to one of the entrants if $s_{1}<\phi\left(s_{(1)}\right)$.

There are, at least, two typical situations in privatizations, and also in procurement and takeover contests, in which the first best allocates to the incumbent and the second best to one of the entrants. The first situation arises due to technological differences between the incumbent and the entrants of the sort described in the Introduction. The second arises when the common value is a dichothomus variable and has been illustrated by Boone and Goeree (2009) and Hernando-Veciana and Michelucci (2011).

Proposition 1. If there is an open set of types for which the first best allocates to the incumbent and the second best to one of the entrants, then there is no equilibrium of the open ascending auction that implements the second best.

Proof. We argue by contradiction. We assume an equilibrium that implements the second best and show that there are incentives to deviate. Note that the argument does not rely on the specific tie breaking rule assumed, as long as it does not allocate, with probability one, to the entrant of highest type.

In our proof, we pick an entrant of type $s^{*}$, an incumbent of type $s_{1}^{*}$ and an $\epsilon>0$, such that (i) $s_{1}^{*}<\phi\left(s^{*}\right)$; (ii) $v\left(s^{*}+\epsilon, s_{1}^{*}\right)-\hat{v}\left(s_{1}^{*}\right)<0$ (and hence $v\left(s_{i}, s_{1}^{*}\right)-\hat{v}\left(s_{1}^{*}\right)<0$ for any $s_{i} \in\left[s^{*}, s^{*}+\epsilon\right]$ ); and (iii), $v\left(s_{i}, s_{1}\right)-\hat{v}\left(s_{1}\right)$ crosses zero at most once and from above as we vary $s_{1}$ in $\left[0, s_{1}^{*}\right]$ for any $s_{i} \in\left[s^{*}, s^{*}+\epsilon\right]$. Types that satisfy (i) and (ii) exist as a direct consequence of the conditions of the proposition and the continuity of $v$. Note that if these types do not satisfy (iii), it must be because another incumbent's type $s_{1}^{* \prime}<s_{1}^{*}$ exists that together with $s^{*}$ and a sufficiently small $\epsilon$ satisfies (i), (ii) and (iii).

A key result in our proof is that along the equilibrium path only the entrant with largest type is active at price $v\left(s_{1}^{*}\right)$ if his type lies in $\left[s^{*}, s^{*}+\epsilon\right]$ and the incumbent is also active. If this did not hold, then we would have a rush, which is not compatible with the starting assumption that the open ascending auction implements the second best.

We show that an entrant of type $s^{*}$ has a strictly profitable deviation, to behave as a type $s^{*}+\epsilon$ (according to the assumed equilibrium strategy) until either (a) the incumbent quits, say at price $p$, or (b) all the other entrants quit. If (a) occurs first, the deviating entrant remains in the auction until the price goes above $v\left(s^{*}, \hat{v}^{-1}(p)\right)$. If (b) occurs first, the deviating entrant remains in the auction 
until the price goes above $\hat{v}\left(\phi\left(s^{*}\right)\right)$.

To see why the deviation is strictly profitable, we first note that our entrant wins in the same cases (and pays the same prices) with the original strategy as with the deviation, if the highest of the other entrants' types, say $y_{(1)}$, is less than $s^{*}$. We also note that our entrant loses with both the original strategy and the deviation if $y_{(1)}$ is greater than $s^{*}+\epsilon$. Both statements hold true as a consequence of the fact that the strategy profile implements the second best and the second best is monotone, and that after (a) or (b), our entrant plays the same actions with the original strategy and with the deviation.

Suppose now that $y_{(1)} \in\left(s^{*}, s^{*}+\epsilon\right)$. The fact that the second best only allocates to the entrant with the highest type means that the deviating entrant loses, and hence gets zero payoffs, when playing the original strategy. We shall show that the deviation gives the deviating entrant strictly positive expected profits. To prove so, let $\tau$ be the value of $s_{1} \in\left[0, s_{1}^{*}\right]$ such that $v\left(y_{(1)}, s_{1}\right) \geq \hat{v}\left(s_{1}\right)$ if $s_{1} \in[0, \tau)$ and $v\left(y_{(1)}, s_{1}\right)<\hat{v}\left(s_{1}\right)$ if $s_{1} \in\left(\tau, s_{1}^{*}\right]$. That $\tau$ exists follows from (iii). We distinguish two cases depending on whether or not the incumbent's type $s_{1}$ is less than $\tau$. If it is the case, the deviating entrant makes non negative payoffs. The explanation differs depending on whether (a) or (b) occurs first. In the former case, the explanation is that our entrant loses because it is outbid by the entrant with largest type $y_{(1)}$ since $s_{1}<\tau$ means that $v\left(y_{(1)}, s_{1}\right) \geq \hat{v}\left(s_{1}\right)$ and hence the entrant of type $y_{(1)}$ raises his bid after (a) up to $v\left(y_{(1)}, s_{1}\right)$, which is greater than the deviating entrant's bid $\max \left\{\hat{v}\left(s_{1}\right), v\left(s^{*}, s_{1}\right)\right\}$. In case (b), the explanation is that our entrant can guarantee zero payoffs by quitting immediately after the other entrants, and our proposed game play after (b) is optimal and thus must give non negative payoffs.

To conclude the proof we argue that if the incumbent's type is greater than $\tau$, the expected payoffs are no less than

$$
\int_{\tau}^{\phi\left(s^{*}\right)}\left(v\left(s^{*}, s_{1}\right)-\hat{v}\left(s_{1}\right)\right) d F_{1}\left(s_{1}\right)
$$

which is strictly positive by definition of $\phi\left(s^{*}\right)$. To see why these are the expected payoffs, note first that if $s_{1} \in\left[\tau, s_{1}^{*}\right), v\left(s^{*}, s_{1}\right)-\hat{v}\left(s_{1}\right)$ is a lower bound for the payoffs because $v\left(y_{(1)}, s_{1}\right)-\hat{v}\left(s_{1}\right)<0$ implies that all the entrants still active quit immediately after the incumbent. Hence, the minimum payoff for the deviating entrant occurs when he wins, in which case he pays the incumbent's bid $\hat{v}\left(s_{1}\right)$. Second, if $s_{1} \geq s_{1}^{*}$, our key result above implies that (b) occurs and hence the deviating entrant wins if and only if $s_{1}<\phi\left(s^{*}\right)$. In this case, the price is equal to the incumbent's bid $\hat{v}\left(s_{1}\right)$. 


\subsection{Equilibrium Rushes and Efficiency Losses}

In this subsection, we characterize the equilibrium of the open ascending auction under the conditions of Proposition 1. To do so, we impose some additional assumptions that simplify the description of the equilibrium: (I) all the entrants' types follow the same distribution $F$ with density $f$, i.e. $F_{j}=F$ for all $j \neq 1$; (II) there are only two entrants, i.e. $n=2$; (III) $v\left(s_{i}, s_{1}\right)-\hat{v}\left(s_{1}\right)$ is strictly increasing in $s_{1} ;(\mathrm{IV}) \int_{0}^{1}\left(v\left(0, s_{1}\right)-\hat{v}\left(s_{1}\right)\right) d F_{1}\left(s_{1}\right)>0$; and $(\mathrm{V}) v(0,0)-\hat{v}(0)<0$.

Relaxing (I) requires solving several versions of the differential equations in (5), one per each different distribution of entrants. Note that an additional source of inefficiencies arises when we relax (I), because there is no guarantee that the solutions to the corresponding equations imply an equilibrium in which the entrant that quits first has the lower type among the entrants. Relaxing (II) requires characterizing the bid behavior in information sets in which the incumbent and three or more entrants are active. The only complication is the notational burden. Assumption (III) implies that $\rho$ is a decreasing function (strictly if $\rho\left(s_{1}\right) \in(0,1)$ ), Assumptions (III) and (IV) imply that $\phi\left(s_{i}\right)=1$ for any $s_{i} \in(0,1]$ (that is the second best never allocates to the incumbent), and Assumption (V) that $\rho(0)>0$. Assumptions (III)-(V) guarantee that the set of types for which the conditions of Proposition 1 apply is not empty and lies at the bottom of the support of all the bidders' types. Although our solution can be easily adapted to a general setting, the notation becomes cumbersome and the characterization may require solving several differential equation as in (5), one for each disconnected set of types in which the conditions of Proposition 1 apply.

We propose an equilibrium in which the arguments in the previous section pin down: i) the incumbent's strategy; ii) the prices at which entrants quit in information sets in which the incumbent has already quit; iii) the prices at which the entrants quit in information sets in which the other entrant has already quit (i.e. the only other active bidder is the incumbent.) It is worth noting that after an entrant quits, the other entrant always outbids the incumbent since $\phi\left(s_{i}\right)=1$ for any $s_{i} \in[0,1]$. Thus, it only remains to characterize the prices at which the entrants' quit in equilibrium in information sets in which all the bidders are still active. In our proposed equilibrium, an entrant of type $s_{i}$ in these information sets quits at $\hat{v}\left(\gamma\left(s_{i}\right)\right)$, where $\gamma$ is equal to the (increasing) solution to the differential equation (5) in the set $\left\{\left(s_{i}, s_{1}\right): s_{1} \in[0,1], s_{i} \in\left[0, \rho\left(s_{1}\right)\right)\right\}$ with initial condition $\gamma(0)=0$.

$$
\beta \int_{\gamma\left(s_{i}\right)}^{1}\left(v\left(s_{i}, s_{1}\right)-\hat{v}\left(s_{1}\right)\right) \frac{d F_{1}\left(s_{1}\right)}{1-F_{1}\left(\gamma\left(s_{i}\right)\right)}+(1-\beta) \frac{F\left(\rho\left(\gamma\left(s_{i}\right)\right)\right)-F\left(s_{i}\right)}{1-F\left(s_{i}\right)} \frac{1}{2}\left(v\left(s_{i}, \gamma\left(s_{i}\right)\right)-\hat{v}\left(\gamma\left(s_{i}\right)\right)\right)=0,
$$


where $\beta \equiv \frac{f\left(s_{i}\right)\left(1-F_{1}\left(\gamma\left(s_{i}\right)\right)\right)}{f\left(s_{i}\right)\left(1-F_{1}\left(\gamma\left(s_{i}\right)\right)\right)+f_{1}\left(\gamma\left(s_{i}\right)\right) \gamma^{\prime}\left(s_{i}\right)\left(1-F\left(s_{i}\right)\right)} .{ }^{16}$ We let $\bar{s}$ be the value at which $\gamma$ reaches the boundary of the set $\left\{\left(s_{i}, s_{1}\right): s_{1} \in[0,1], s_{i} \in\left[0, \rho\left(s_{1}\right)\right)\right\}$ and assume that $\gamma\left(s_{i}\right)$ is equal to one for any $s_{i}>\bar{s}$. Note that $\rho(\gamma(\bar{s}))=\bar{s}$. Figure 1 illustrates the functions $\gamma$ and $\rho$. The function $\gamma$ identifies a frontier that separates two areas (top area and bottom area). The bottom area depicts the signal profiles for which an entrant suffers ex-post regret when winning, while the top area depicts the signal profiles for which an entrant gets positive profits when winning. The function $\rho$ also identifies a frontier that separates two areas (top area and bottom area). The bottom (top) area depicts the signal profiles for which the entrant exits before (after) the incumbent. Thus, the area below both frontiers identifies the set of signal profiles, such that the incumbent quits before an entrant of type $s$, and such entrant finds it optimal to quit immediately, as he would make a loss if he won at that price.

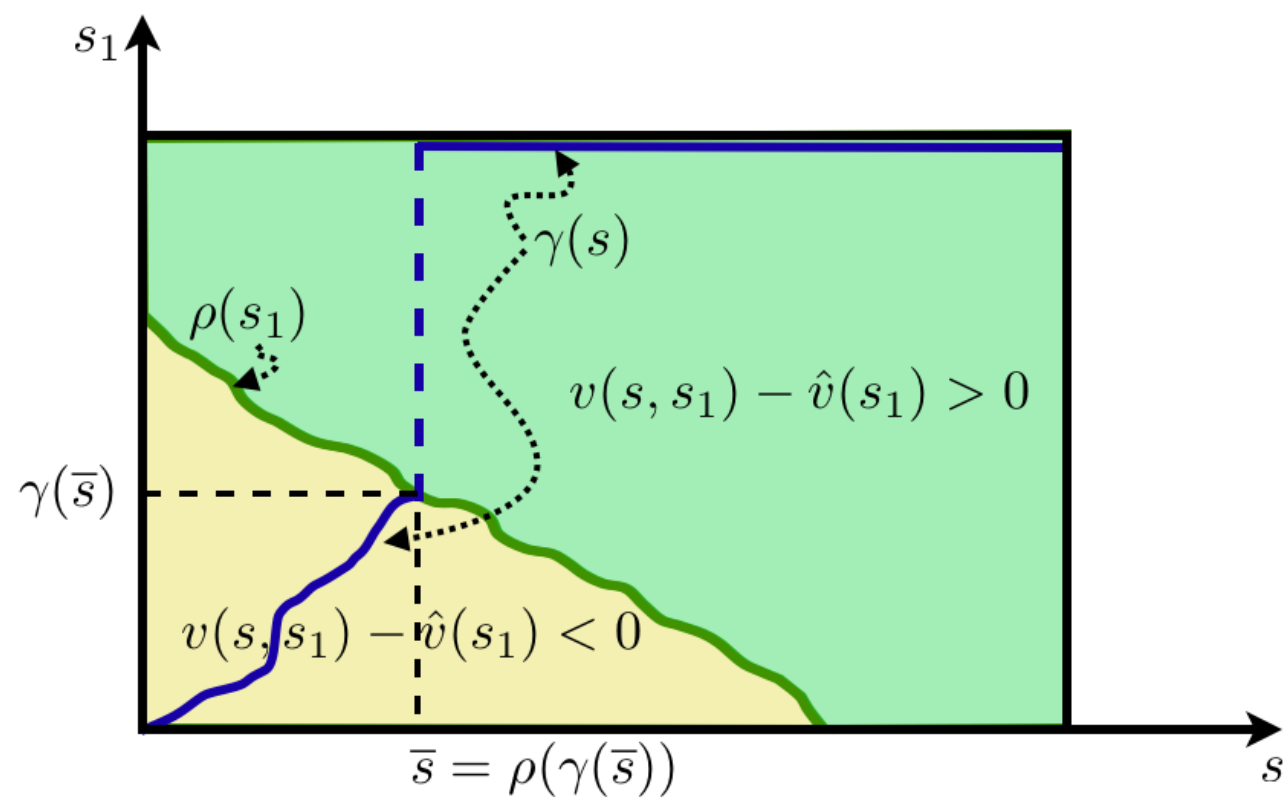

Figure 1: Examples of the functions $\gamma$ and $\rho$.

This differential equation implies that an entrant of type $s_{i} \in(0, \bar{s})$ does not have incentives to

${ }^{16}$ That this differential equation has a unique solution follows from applying standard results, e.g. Theorem 2.3 in Coddington and Levinson (1984), to this transformation:

$$
\gamma^{\prime}\left(s_{i}\right)=\frac{f\left(s_{i}\right) \int_{\gamma\left(s_{i}\right)}^{1}\left(v\left(s_{i}, s_{1}\right)-\hat{v}\left(s_{1}\right)\right) d F_{1}\left(s_{1}\right)}{f_{1}\left(\gamma\left(s_{i}\right)\right) \frac{F\left(\rho\left(\gamma\left(s_{i}\right)\right)\right)-F\left(s_{i}\right)}{2}\left(\hat{v}\left(\gamma\left(s_{i}\right)\right)-v\left(s_{i}, \gamma\left(s_{i}\right)\right)\right)} .
$$

The solution is strictly increasing. 
change her bid marginally when all the bidders play our proposed equilibrium. To see why, note that a marginal deviation (upwards) only matters if it allows the bidder to outbid the lowest of the other bidders' bids (and thus, avoids being the first bidder quitting), i.e. in the marginal event of breaking a tie with the lowest bid of the other bidders. Conditional on this event, two things may happen. First, if it is the other entrant who bids the lowest, which occurs with conditional probability $\beta$, then our entrant competes in the last stage against the incumbent until the incumbent quits. This gives our entrant expected positive profits equal to the expression that is multiplied by $\beta$ in Equation (5). Second, it is the incumbent who bids the lowest, which occurs with conditional probability $1-\beta$, then our entrant quits immediately, since the incumbent's type is equal to $\gamma\left(s_{i}\right)$ and $s_{i}<\bar{s}$ means that $s_{i}<\rho\left(\gamma\left(s_{i}\right)\right)$. In this case, our entrant makes expected losses equal to $\frac{1}{2}\left(v\left(s_{i}, \gamma\left(s_{i}\right)\right)-\hat{v}\left(\gamma\left(s_{i}\right)\right)\right)$ if the other entrant also quits immediately after the incumbent, which occurs with conditional probability $\frac{F\left(\rho\left(\gamma\left(s_{i}\right)\right)\right)-F\left(s_{i}\right)}{1-F\left(s_{i}\right)}$.

Proposition 2. The proposed strategies are an equilibrium of the open ascending auction under assumptions (I)-(V).

Proof. The incumbent has no incentive to deviate. Additionally, we have already argued that our proposed strategy for the entrants is a best response in information sets in which one bidder has already quit. Hence, it is sufficient for our proof to assume the former play and show that an entrant does not have incentives to deviate in information sets in which no bidder has quit yet. We restrict attention to deviations in $[\hat{v}(0), \hat{v}(1)]$. An entrant that quits at a price strictly less than $\hat{v}(0)$ loses with probability one, as when quitting at price $\hat{v}(0)$. An entrant cannot quit at a price strictly larger than $\hat{v}(1)$ in information sets in which the incumbent is still active, because the incumbent quits before the price reaches $\hat{v}(1)$. We next compute the expected utility of an entrant of type $s_{i}$ that deviates and plans to quit at a price $b \in[\hat{v}(0), \hat{v}(1)]$. We distinguish three cases depending on who quits first. Denote by $s_{j}$ the other entrant's type. First, if the deviating entrant quits first, he makes zero payoffs. Second, if the other entrant quits first (i.e. $\left.\hat{v}\left(\gamma\left(s_{j}\right)\right)<\min \left\{b, \hat{v}\left(s_{1}\right)\right\}\right)$, the deviating entrant wins and pays the incumbent's exit price, deriving expected payoffs equal to: ${ }^{17}$

$$
\int_{0}^{\gamma^{-1}\left(\hat{v}^{-1}(b)\right)} \int_{\gamma\left(s_{j}\right)}^{1}\left(v\left(s_{i}, s_{1}\right)-\hat{v}\left(s_{1}\right)\right) d F_{1}\left(s_{1}\right) d F\left(s_{j}\right) .
$$

Third, if the incumbent quits first (i.e. $\hat{v}\left(s_{1}\right)<\min \left\{\hat{v}\left(\gamma\left(s_{j}\right)\right), b\right\}$ ), we distinguish two subcases depending on whether the deviating entrant quits immediately after the incumbent (i.e. $\left.v\left(s_{i}, s_{1}\right)-\hat{v}\left(s_{1}\right)<0\right)$.

\footnotetext{
${ }^{17}$ We adopt the convention that $\gamma^{-1}\left(s_{1}\right)=\bar{s}$ for $s_{1} \in[\gamma(\bar{s}), 1]$.
} 
If this is the case, the deviating entrant wins and pays the incumbent's bid $\hat{v}\left(s_{1}\right)$ with probability $1 / 2$ when the other entrant also quits (i.e. $s_{j}<\rho\left(s_{1}\right)$ ). The expected payoffs derived from this subcase are equal to: ${ }^{18}$

$$
\int_{0}^{\hat{v}^{-1}(b)} \int_{\min \left\{\gamma^{-1}\left(s_{1}\right), \rho\left(s_{1}\right)\right\}}^{\rho\left(s_{1}\right)} \frac{1}{2}\left(v\left(s_{i}, s_{1}\right)-\hat{v}\left(s_{1}\right)\right)^{-} d F\left(s_{j}\right) d F_{1}\left(s_{1}\right) .
$$

The other subcase arises when $v\left(s_{i}, s_{1}\right)-\hat{v}\left(s_{1}\right) \geq 0$. Then, the deviating bidder remains active until the price reaches his value $v\left(s_{i}, s_{1}\right)$ and, thus, wins if his value is greater than the price at which the other entrant quits. The expected payoffs derived from this subcase are equal to:

$$
\int_{0}^{\hat{v}^{-1}(b)} \int_{\gamma^{-1}\left(s_{1}\right)}^{1}\left(v\left(s_{i}, s_{1}\right)-\max \left\{\hat{v}\left(s_{1}\right), v\left(s_{j}, s_{1}\right)\right\}\right)^{+} d F\left(s_{j}\right) d F_{1}\left(s_{1}\right),
$$

since $\max \left\{\hat{v}\left(s_{1}\right), v\left(\tilde{s}, s_{1}\right)\right\}$ is the proposed bid for a type $\tilde{s}$.

The sum of the last three equations satisfies: (i) increasing differences with respect to $s_{i}$ and $b$, i.e. the cross-differential with respect to $s_{i}$ and $b$ is positive; (ii) that its differential with respect to $b$ is equal to zero for $s_{i} \in[0, \bar{s}]$ and $b=\hat{v}\left(\gamma\left(s_{i}\right)\right)$, i.e. the entrant does not have incentives to deviate locally; and (iii), that the resulting expression is constant in $b$ for any $b$ in $[\hat{v}(\gamma(\bar{s})), \hat{v}(1)]$ and $s_{i}=\bar{s}$. (i) is straightforward, (ii) follows from the definition of $\gamma$ and (iii) because each of the three equations are constant in $b$ for any $b$ in $[\hat{v}(\gamma(\bar{s})), \hat{v}(1)]$ and $s_{i}=\bar{s}$ : the first one because $\gamma^{-1}(b)=\bar{s}$; the second one because $v\left(\bar{s}, s_{1}\right)-\hat{v}\left(s_{1}\right) \geq 0$ for any $s_{1} \geq \gamma(\bar{s})$ since $v(\bar{s}, \gamma(\bar{s}))-\hat{v}(\gamma(\bar{s}))=0$ and we assume (III); and the third one because $\gamma^{-1}\left(s_{1}\right)=\bar{s}$ for $s_{1} \in[\gamma(\bar{s}), 1]$. (i)-(iii) imply that for any $s_{i} \in[0,1]$ the sum of the above three equations is maximized by fixing $b=\hat{v}\left(\gamma\left(s_{i}\right)\right)$ as desired.

In our equilibrium, there are rushes. They occur when the vector of types $\left(s_{1}, s_{2}, s_{3}\right)$ satisfies $s_{1}<\gamma\left(s_{i}\right)$ and $s_{i}<\rho\left(s_{1}\right), i=2,3$. The former condition implies that the incumbent is the first bidder to quit, and the latter that both entrants quit after the incumbent. The proposition below illustrates a special case where the probability of rushes is arbitrarily close to one. It points out that the reason why rushes can arise with very high probability is that entrants can find it profitable to face losses with high probability if they expect very high profits when a rush does not occur.

Proposition 3. Suppose that $\hat{v}\left(s_{1}\right)=s_{1}+1$ and $v\left(s_{i}, s_{1}\right)=s_{i}+\frac{\alpha}{\delta-s_{1}}$ where $\alpha>0$ and $\delta \equiv \frac{1}{1-e^{-\frac{1}{\alpha^{2}}}}$, and that $F$ and $F_{1}$ are uniform. ${ }^{19}$ In equilibrium, the probability that a rush occurs tends to one as

\footnotetext{
${ }^{18}$ We adopt the convention that $(a)^{-}$is equal to $a$ if $a<0$ and zero otherwise, and $(a)^{+}$is equal to $a$ if $a>0$ and zero otherwise.

${ }^{19}$ Although the value functions do not satisfy (III), we can also construct an equilibrium as in Proposition 2 . To see why, note that in that construction, the role of (III) is to guarantees three properties: $\phi\left(s_{i}\right)=1$ for $s_{i} \in[0,1]$; the
} 
$\alpha$ goes to zero. In the limit, the good is allocated between the two entrants with equal probability and independently of their types.

Proof. To prove the proposition, we show that both $\rho\left(s_{1}\right)$ and $\gamma\left(s_{i}\right)$ tend to one as $\alpha$ goes to zero $\forall$ $s_{1} \in[0,1)$ and $\forall s_{i} \in(0,1]$, respectively. The former is straightforward since by definition $\rho\left(s_{1}\right)=$ $\min \left\{1, s_{1}+1-\frac{\alpha}{\frac{1}{1-e^{-\frac{1}{\alpha^{2}}}}-s_{1}}\right\}$, and $\lim _{\alpha \rightarrow 0} \frac{\alpha}{\frac{1}{1-e^{-\frac{1}{\alpha^{2}}}}-s_{1}}=0$ for any $s_{1} \in[0,1)$.

To prove that $\gamma\left(s_{i}\right)$ tends to one for any $s_{i} \in(0,1]$, we argue by contradiction. Suppose that an $s_{i} \in(0,1]$ exists, for which $\gamma\left(s_{i}\right)$ remains below and away from one as $\alpha$ tends to zero. Note that by definition $\gamma$ satisfies:

$$
\gamma\left(s_{i}\right)=\int_{0}^{s_{i}} \frac{\int_{\gamma\left(\tilde{s}_{i}\right)}^{1}\left(\tilde{s}_{i}+\frac{\alpha}{\frac{1}{1-e^{-\frac{1}{\alpha^{2}}}}-s_{1}}-s_{1}-1\right) d s_{1}}{\frac{\rho\left(\gamma\left(\tilde{s}_{i}\right)\right)-\tilde{s}_{i}}{2}\left(\gamma\left(\tilde{s}_{i}\right)+1-\tilde{s}_{i}-\frac{\alpha}{\frac{1}{1-e^{-\frac{1}{\alpha^{2}}}}-\gamma\left(\tilde{s}_{i}\right)}\right)} d \tilde{s}_{i},
$$

where recall that $\gamma\left(\tilde{s}_{i}\right)$ also remains below and away from one for any $\tilde{s}_{i} \in\left[0, s_{i}\right]$ because $\gamma$ is increasing. The denominator in Equation (6) tends to $\frac{1-\tilde{s}_{i}}{2}\left(\gamma\left(\tilde{s}_{i}\right)+1-\tilde{s}_{i}\right)>0$ as $\alpha$ tends to zero and the integral in the numerator is equal to:

$$
\tilde{s}_{i}\left(1-\gamma\left(\tilde{s}_{i}\right)\right)+\frac{1}{\alpha}+\alpha \ln \left(1-\gamma\left(\tilde{s}_{i}\right)+e^{-\frac{1}{\alpha^{2}}} \gamma\left(\tilde{s}_{i}\right)\right)-\frac{1-\gamma\left(\tilde{s}_{i}\right)^{2}}{2}-\left(1-\gamma\left(\tilde{s}_{i}\right)\right),
$$

which diverges to infinity as $\alpha$ tends to zero. This contradicts the fact that $\gamma\left(s_{i}\right)$ is below and away from one.

\section{Other Standard Auctions}

We have shown that rushes cause the open ascending auction to be inefficient. Since rushes occur because the format of this auction type allows all active bidders to aggregate the same negative information, it is natural to explore whether other standard formats that do not allow information aggregation can be optimal. Indeed, we show, for a particular case of the setup discussed in the previous section, that the allocation implemented by the open ascending auction is the worst among the standard auctions: all other standard auctions except the open ascending auction implement the second best. To the best of our knowledge, no such result previously existed in the auction literature. solution to Equation (6) with initial condition $(0,0)$ increases until the point $(\bar{s}, \gamma(\bar{s}))$ where it crosses with the graph of $\rho$; and $v\left(\bar{s}, s_{1}\right)-\hat{v}\left(s_{1}\right)>0$ for $s_{1}>\gamma(\bar{s})$. It can be shown that these three properties are verified in the example for $\alpha$ small. 
Proposition 4. All the standard auctions except the open ascending auction (i.e. the first price auction, the Dutch auction and the second price auction) implement the second best if $\phi(0)=1$, $F_{i}=F$ for all ${ }^{20} i$ and:

$$
\int_{0}^{1} v\left(0, s_{1}\right) d F_{1}\left(s_{1}\right) \geq \hat{v}(1)
$$

Proof. We propose some strategies, check that they form an equilibrium and show that they implement the second best. The procedure is identical for each of the standard auctions (excepting the open ascending that has been analyzed already in Section 4.1). Let $V\left(s_{i}\right) \equiv \int_{0}^{1} v\left(s_{i}, s_{1}\right) d F_{1}\left(s_{1}\right)$ for any $i \neq 1$ and consider the unique symmetric equilibrium of each of the standard auctions for $n$ bidders with value function $V\left(s_{i}\right)$ and types i.i.d according to a distribution function $F$, see for instance Krishna (2002). Our proposed equilibrium is that the entrants use this strategy and the incumbent bids her value. To see why this strategy profile is an equilibrium of our model, note that all the entrants bids are larger than $V(0)$ and hence than $\hat{v}(1)$. This means that neither the incumbent nor the entrants have incentives to deviate: the incumbent, because she does not find it profitable to win at any price at which she can win and indeed her proposed bid always loses; and the entrants, because the event of winning or losing is not informative of the incumbent type $s_{1}$ and so entrants compete as in a private value auction. Finally, when all bidders follow the proposed strategies, the good is allocated to the entrant with highest type, as required by the second best when $\phi(0)=1$.

Under the conditions of the proposition, the second best allocates to the entrant with the largest type. An equilibrium that implements this allocation in each of the standard auctions except the open ascending auction is that the incumbent bids her value, and entrants bid as if there were no incumbent. This is the case, for instance, for Example 1 of Section 4 , for which we have: $b_{1}\left(s_{1}\right)=\frac{1}{2}+s_{1}$, $b_{i}\left(s_{i}\right)=\frac{3}{2}+\frac{s_{i}}{3}, \forall i$, for the second price auction; and, $b_{1}\left(s_{1}\right)=\frac{1}{2}+s_{1}, b_{i}\left(s_{i}\right)=\frac{3}{2}+\frac{s_{i}}{6}$, for the first price auction and the Dutch auction. Certainly, this argument only applies under the special conditions of the proposition. In general, standard auctions do not implement the second best because, beyond the special case of this section, the second best requires some information to be aggregated. Using a multi-stage second price auction allows to achieve the second best. The next section presents such solution.

\footnotetext{
${ }^{20}$ The assumption $F_{i}=F$ for all $i$ is not necessary in the case of the second price auction.
} 


\section{A Multi-Stage Auction}

In this section, we show that the two-stage sealed bid auction analyzed by Perry, Wolfstetter, and Zamir (2000) has an equilibrium that implements the second best allocation. In a first stage, all bidders submit a bid, and in a second stage, the first stage bids and identities of all the bidders but the two highest, the top bidders, are made public and the top bidders are allowed to revise their bids upwards to make their final bids. The good is allocated to the top bidder that submits the highest final bid at a price equal to the final bid of the other top bidder. ${ }^{21,22}$

As pointed out by Perry, Wolfstetter, and Zamir (2000), this mechanism shares many features with the open ascending auction. To underline the parallelism, note that the open ascending auction is strategically equivalent to the following multi-stage mechanism. The auction starts with all the bidders being active and the minimum price set to zero. At each stage, all active bidders submit a bid larger than the current minimum price. At the end of each stage, the bidder submitting the lowest bid becomes inactive, her identity and bid are made public and the current minimum price is reset to her bid. The auction ends when no more than one bidder remains active. This bidder wins and pays a price equal to the bid of the last bidder declared inactive.

Our two-stage sealed bid auction differs from this mechanism in two aspects. First, our auction only has two stages. Second, in our auction, the minimum price set after the first stage is different across bidders and it is equal to the bidder's bid in the previous stage. The second difference is key to our results. By allowing for exogenous differences across bidders in the minimum prices, it avoids ties in case bidders choose their minimum feasible bids without upsetting the good properties of the open ascending auction. The first difference does not seem essential for our results. Increasing the number of stages allows bidders to condition their bids on more information and thus expand the set of allocations that could be potentially implemented. In our setting, as in Perry, Wolfstetter and Zamir's (2000), two stages prove to be sufficient, and we expect our results to hold true in a general

\footnotetext{
${ }^{21}$ We do not make explicit the tie-breaking rule in this section because it is not relevant for our analysis because ties occur with zero probability in our equilibrium.

${ }^{22} \mathrm{An}$ alternative rule is to reveal only the identity of the two bidders that qualify to the second stage, while keeping unaltered all other details. This alternative rule is more parsimonious in the amount of information that is transmitted across stages, and therefore simplifies some of the analysis below and makes the interpretation of the break even condition (8) easier, see footnote 27. However, we do not observe it in practice. The reason might be that it does not allow for the aggregation of the private information of the non qualifying entrants, which is irrelevant given our assumptions, but in general might matter.
} 
multi-stage version of our proposed auction.

We can use the same arguments used in Section 4.1 to analyse the open ascending auction to conclude that: it is weakly dominant for the incumbent to bid her value $\hat{v}\left(s_{1}\right)$, both in the first and in the second stage ${ }^{23}$ the optimal bid in the second stage of an entrant top bidder of type $s$ is either $v\left(s_{i}, \hat{v}^{-1}(p)\right)$ or her first stage bid, whichever is larger; and if the incumbent is the other top bidder, an entrant of type $s$ that bids less than $\hat{v}\left(\phi\left(s_{i}\right)\right)$ in the first stage, finds it optimal to increase his bid in the second stage to $\hat{v}\left(\phi\left(s_{i}\right)\right)$.

The former play implies that the following property must be verified in information sets in which the top bidders are entrants:

Property P1: The top bidder entrant with higher first stage bid wins if his type is larger than the type of the other top bidder entrant.

Note also that an entrant of type $s_{i}$ finds it weakly dominated to bid less than $v\left(s_{i}, 0\right)$ in either of the two stages. This is his minimum possible value and bidding less could mean losing the opportunity of winning at profitable prices without affecting the price paid in case of winning.

We propose an equilibrium in which the arguments above pin down the incumbent's strategy and the entrants' bids in the second stage. Further, in our proposed equilibrium an entrant with type $s_{i}$ uses a strictly increasing bid function $b\left(s_{i}\right)$ in the first stage that it is equal to $v\left(s_{i}, 0\right)$ if either $v\left(s_{i}, 0\right) \geq \hat{v}(1)$ or $\phi\left(s_{i}\right)=0,{ }^{24}$ and otherwise it is equal to $\hat{v}\left(\psi\left(s_{i}\right)\right)$ where $\psi\left(s_{i}\right) \in\left(0, \phi\left(s_{i}\right)\right)$ is a strictly

\footnotetext{
${ }^{23}$ Note that the incumbent's first stage bid cannot affect the second stage bid of her opponent simply because first stage bids are not revealed.

${ }^{24}$ Note that if $v\left(s_{i}, 0\right) \geq \hat{v}(1)$ our proposed bid is greater than $\hat{v}(1)$ whereas if $\phi\left(s_{i}\right)=0$, our proposed bid is less than $\hat{v}(0)$. The former is direct and the latter is because $\phi\left(s_{i}\right)=0$ requires that $v\left(s_{i}, 0\right)-\hat{v}(0) \leq 0$.
} 
increasing function implicitly defined by: ${ }^{25,26}$

$$
\int_{0}^{\psi\left(s_{i}\right)}\left(v\left(s_{i}, s_{1}\right)-\hat{v}\left(\psi\left(s_{i}\right)\right)\right)^{-} d F_{1}\left(s_{1}\right)+\int_{\psi\left(s_{i}\right)}^{\phi\left(s_{i}\right)}\left(v\left(s_{i}, s_{1}\right)-\hat{v}\left(s_{1}\right)\right) d F_{1}\left(s_{1}\right)=0 .
$$

Condition (8) can be interpreted as a break even condition for a type $s_{i}$ entrant conditional on his first stage bid, $\hat{v}\left(\psi\left(s_{i}\right)\right)$, resulting in a tie with the highest of the other entrants. Conditional on such event, there are two possibilities to be considered: the incumbent placed a bid lower than $\hat{v}\left(\psi\left(s_{i}\right)\right)$, or above $\hat{v}\left(\psi\left(s_{i}\right)\right)$. The sum of the expected profits under these two possibilities is equal to zero by construction, which means that expected expected profits must be non positive in one case, and non negative in the other.The non positive part has to corresponds to the case for which the incumbent bid is below the entrant's first stage bid. The reason is that in such case the top bidders are the two entrants, and since they have the same type, they cannot gain strictly positive profits. This non positive component is captured by the first integral in the left hand side (LHS) of Equation (8). The non negative part corresponds to the case the incumbent bid is above the entrant's first stage bid. In that case, the entrant that breaks the tie qualifies with the incumbent. Expected profits in this case cannot be strictly negative, as in the second stage the entrant can always opt not to revise his bid, which would yield zero profits. This non negative component is captured by the first integral in the left hand side (LHS) of Equation (8). ${ }^{27}$

Notice that also in a second price auction with private values the equilibrium bid is derived by a break even condition. However, in private values, conditional on a tie, there is ex-post break even, while here, conditional on a tie with the highest of the other entrants, the break even is only in expectations. To continue the parallelism with the second price auction with private value, recall that a bidder never regrets having won or lost, given the ex-post information about the bidding of the other bidders. While this is not the case in our model, what is true is that the entrant would not regret

\footnotetext{
${ }^{25}$ If $\phi\left(s_{i}\right) \in(0,1]$, one can deduce that there is a unique $\psi\left(s_{i}\right) \in\left(0, \phi\left(s_{i}\right)\right)$ that solves Equation $(7)$ from the fact that its left hand side is a continuous strictly decreasing function in $\psi\left(s_{i}\right)$, strictly positive at $\psi\left(s_{i}\right)=0$ and strictly negative at $\psi\left(s_{i}\right)=\phi\left(s_{i}\right)$. The first fact is direct, the second fact follows from the definition of $\phi$ using that $\phi\left(s_{i}\right)>0$, and the third fact because either $\phi\left(s_{i}\right) \in(0,1)$ and then the definition of $\phi$ requires that $v\left(s_{i}, \phi(s)\right)=\hat{v}\left(\phi\left(s_{i}\right)\right)$ and hence $v\left(s_{i}, s_{1}\right)<\hat{v}\left(\phi\left(s_{i}\right)\right)$ for $s_{1}<\phi\left(s_{i}\right)$, or $\phi\left(s_{i}\right)=1$ and then it follows from the condition that $v\left(s_{i}, 0\right)<\hat{v}(1)$. Finally, that the left hand side of Equation (7) is strictly increasing in $s_{i}$ means that $\psi\left(s_{i}\right)$ is a strictly increasing function.

${ }^{26}$ That $b\left(s_{i}\right)$ is strictly increasing follows from the fact that $v(., 0), \hat{v}$ and $\psi$ are strictly increasing functions and the optimality conditions of the problem that defines $\phi$ imply that $v\left(s_{i}, 0\right)-\hat{v}(0) \leq 0$ if $\phi\left(s_{i}\right)=0$.

${ }^{27}$ Note that if we had used the rules in footnote 22 condition (8) would be modified to include also the positive terms in the first term of the LHS, and we could interpret the first stage bid as the maximum reservation price at which an entrant would be happy to enter a SPA against the incumbent.
} 
his first stage bid if he were informed about the bidding of the other entrants. The proof verifies that indeed there are no profitable deviations.

The next proposition shows that the proposed strategies are indeed an equilibrium.

Proposition 5. The proposed strategies are an equilibrium.

Proof. We show in this proof that when all the bidders follow the proposed strategies, an entrant does not have incentives to deviate in the first stage. This is sufficient because the incumbent does not have incentives to deviate, and we have already argued that our proposed strategy for the entrants is a best response in the second stage. It is still necessary to specify how a deviating entrant plays after a first stage bid $p>\hat{v}\left(\phi\left(s_{i}\right)\right)$ when he is a top bidder together with the incumbent. Adapting the arguments used for the case $p \leq \hat{v}\left(\phi\left(s_{i}\right)\right)$ at the beginning of Section 4.1, one can conclude that the optimal bid is equal to $p$ if $p>\hat{v}(1)$, and if $p \in\left(\hat{v}\left(\phi\left(s_{i}\right)\right), \hat{v}(1)\right]$, it is equal to $\hat{v}\left(\hat{\phi}\left(s_{i}, p\right)\right)$ where: ${ }^{28}$

$$
\begin{aligned}
\hat{\phi}\left(s_{i}, p\right) & \equiv \arg \max _{\tilde{s}_{1} \in\left[\hat{v}^{-1}(p), 1\right]} \int_{0}^{\tilde{s}_{1}}\left(v\left(s_{i}, s_{1}\right)-\hat{v}\left(s_{1}\right)\right) d F_{1}\left(s_{1}\right) \\
& =\arg \max _{\tilde{s}_{1} \in\left[\hat{v}^{-1}(p), 1\right]} \int_{\hat{v}^{-1}(\tilde{b})}^{\tilde{s}_{1}}\left(v\left(s_{i}, s_{1}\right)-\hat{v}\left(s_{1}\right)\right) \frac{d F_{1}\left(s_{1}\right)}{1-F_{1}\left(\hat{v}^{-1}(\tilde{b})\right)},
\end{aligned}
$$

for any $\tilde{b}$, where $\tilde{b}$ denotes the largest bid revealed in the first stage. The equality follows because the two maximands are an affine transformation of each other with parameters constant in $\tilde{s}_{1} \cdot{ }^{29}$ Clearly, $\phi\left(s_{i}\right)=\hat{\phi}\left(s_{i}, p\right)$ if $p \leq \hat{v}\left(\phi\left(s_{i}\right)\right)$. We assume that the deviating entrant plays these second stage bids.

In our analysis, it is convenient to generalize the definition of $\psi$ to the whole interval $[0,1]$. We let $\psi\left(s_{i}\right) \equiv 0$ for those values of $s_{i}$ such that $\phi\left(s_{i}\right)=0$ and we let $\psi\left(s_{i}\right)=1$ for those values of $s_{i}$ such that $v\left(s_{i}, 0\right)>\hat{v}(1)$.

We first study the incentives of an entrant of type $s_{i}$ to deviate upwards to a bid $p>b\left(s_{i}\right)$. All along the proof, we denote by $y_{(1)}$ the highest type of the other entrants. We show that there are no strict incentives to deviate distinguishing two cases:

(a) If $\hat{v}\left(s_{1}\right)>b\left(y_{(1)}\right)$ (i.e. $\left.s_{1}>\psi\left(y_{(1)}\right)\right)$ our entrant can be top bidder only when the incumbent is the other top bidder, and hence pays price $\hat{v}\left(s_{1}\right)$ if he wins. In this case, bidding $p$ or $b\left(s_{i}\right)$ changes whether the deviating entrant wins only if either (i) $b\left(y_{(1)}\right) \in\left(b\left(s_{i}\right), p\right)$ and $s_{1}<\hat{\phi}\left(s_{i}, p\right)$; or (ii) $b\left(y_{(1)}\right)<b\left(s_{i}\right)$ and $s_{1} \in\left(\phi\left(s_{i}\right), \hat{\phi}\left(s_{i}, p\right)\right) \subset\left(\psi\left(y_{(1)}\right), 1\right]\left(\right.$ since $\left.\phi\left(s_{i}\right) \geq \psi\left(s_{i}\right) \geq \psi\left(y_{(1)}\right)\right)$. If either

\footnotetext{
${ }^{28}$ As for the case of $\phi$, the solution to this maximization problem is unique except in a set of measure zero. It is irrelevant how we define $\hat{\phi}$ in the case of multiple solutions, as a convention we take the minimum solution.

${ }^{29}$ See Footnote 15.
} 
$b\left(y_{(1)}\right)>p$ or $s_{1}>\hat{\phi}\left(s_{i}, p\right)$, our entrant loses with both $b\left(s_{i}\right)$ and $p$, as it is outbid by another entrant and the incumbent in the first stage or by the incumbent in the second, respectively, whereas if $b\left(y_{(1)}\right)<b\left(s_{i}\right)$ and $s_{1}<\phi\left(s_{i}\right)$, our entrant wins with both $b\left(s_{i}\right)$ and $p$. In case (i) and (ii), however, our entrant wins with the bid $p$ but loses with $b\left(s_{i}\right)$. In case (i), this is because our entrant is a top bidder with $p$ but not with $b\left(s_{i}\right)$ and in case (ii) because our entrant outbids the incumbent in the second stage when she bids $p$ in the first stage but not when she bids $b\left(s_{i}\right)$ in the first stage. The expected increase in payoffs that corresponds to case (i) is equal to:

$$
\begin{aligned}
\int_{s_{i}}^{b^{-1}(p)} \int_{\psi\left(y_{(1)}\right)}^{\hat{\phi}\left(s_{i}, p\right)}\left(v\left(s_{i}, s_{1}\right)-\hat{v}\left(s_{1}\right)\right) d F_{1}\left(s_{1}\right) d F\left(y_{(1)}\right)^{n-1} \\
\leq \int_{s_{i}}^{b^{-1}(p)} \int_{\psi\left(y_{(1)}\right)}^{\hat{\phi}\left(s_{i}, p\right)}\left(v\left(y_{(1)}, s_{1}\right)-\hat{v}\left(s_{1}\right)\right) d F_{1}\left(s_{1}\right) d F\left(y_{(1)}\right)^{n-1} \\
\leq \int_{s_{i}}^{b^{-1}(p)} \int_{\psi\left(y_{(1)}\right)}^{\phi\left(y_{(1)}\right)}\left(v\left(y_{(1)}, s_{1}\right)-\hat{v}\left(s_{1}\right)\right) d F_{1}\left(s_{1}\right) d F\left(y_{(1)}\right)^{n-1},(10)
\end{aligned}
$$

where we have used the monotonicity of $v$ in the first inequality and the fact that $\tilde{s}_{1}=\phi\left(y_{(1)}\right)$ maximizes $\int_{\psi\left(y_{(1)}\right)}^{\tilde{s}_{1}}\left(v\left(y_{(1)}, s_{1}\right)-\hat{v}\left(s_{1}\right)\right) d F_{1}\left(s_{1}\right)$ subject to $\tilde{s}_{1} \geq \psi\left(y_{(1)}\right),{ }^{30}$ in the second inequality. The expected increase in payoffs that correspond to case (ii) is equal to:

$$
\int_{0}^{s_{i}} \int_{\phi\left(s_{i}\right)}^{\hat{\phi}\left(s_{i}, p\right)}\left(v\left(s_{i}, s_{1}\right)-\hat{v}\left(s_{1}\right)\right) d F_{1}\left(s_{1}\right) d F\left(y_{(1)}\right)^{n-1}
$$

which is non positive by definition of $\phi$.

(b) If $\hat{v}\left(s_{1}\right)<b\left(y_{(1)}\right)$ (i.e. $s_{1} \leq \psi\left(y_{(1)}\right)$ ), our entrant can only be top bidder with the entrant of type $y_{(1)}$ and hence pays a price equal to $\max \left\{v\left(y_{(1)}, s_{1}\right), \hat{v}\left(\psi\left(y_{(1)}\right)\right)\right\}$ if he wins. Bidding $p$ or $b\left(s_{i}\right)$ changes whether the deviating entrant wins only if $b\left(y_{(1)}\right) \in\left(b\left(s_{i}\right), p\right)$. If $b\left(y_{(1)}\right)<b\left(s_{i}\right)$ our entrant wins with both $b\left(s_{i}\right)$ and $p$, whereas if $b\left(y_{(1)}\right)>p$, our entrant loses with both $b\left(s_{i}\right)$ and $p$. In both cases, this is a consequence of Property P1. If $b\left(y_{(1)}\right) \in\left(b\left(s_{i}\right), p\right)$, then $y_{(1)}>s_{i}$, and our entrant is the top bidder with highest bid if he bids $p$ but he is not when he bids $b\left(s_{i}\right)$. Property P1 implies that he loses when he bids $b\left(s_{i}\right)$. However, he wins with bid $p$ if the other top bidder does not find it profitable to win, i.e. $v\left(y_{(1)}, s_{1}\right) \leq \max \left\{p, v\left(s_{i}, s_{1}\right)\right\}$. In this case, our entrant makes profits $v\left(s_{i}, s_{1}\right)-\max \left\{v\left(y_{(1)}, s_{1}\right), \hat{v}\left(\psi\left(y_{(1)}\right)\right)\right\}$, which are are less than:

$$
v\left(y_{(1)}, s_{1}\right)-\max \left\{v\left(y_{(1)}, s_{1}\right), \hat{v}\left(\psi\left(y_{(1)}\right)\right)\right\}=\left(v\left(y_{(1)}, s_{1}\right)-\hat{v}\left(\psi\left(y_{(1)}\right)\right)\right)^{-} .
$$

\footnotetext{
${ }^{30}$ We are using again a variation of the argument in Footnote 15.
} 
Note that since $b(x)=\hat{v}(\psi(x)), v\left(y_{(1)}, s_{1}\right)<\hat{v}\left(\psi\left(y_{(1)}\right)\right)$ implies that $v\left(y_{(1)}, s_{1}\right)<b\left(y_{(1)}\right)$. Hence, $b\left(y_{(1)}\right)<p$ implies that $v\left(y_{(1)}, s_{1}\right) \leq \max \left\{p, v\left(s_{i}, s_{1}\right)\right\}$, which means, as explained above, that the deviating entrant wins with $p$ whenever $v\left(y_{(1)}, s_{1}\right)<\hat{v}\left(\psi\left(y_{(1)}\right)\right)$. Consequently, the expected increase in payoffs that corresponds to the case $\hat{v}\left(s_{1}\right)<b\left(y_{(1)}\right)$ is less than:

$$
\left.\int_{s_{i}}^{b^{-1}(p)} \int_{0}^{\psi\left(y_{(1)}\right)}\left(v\left(y_{(1)}\right), s_{1}\right)-\hat{v}\left(\psi\left(y_{(1)}\right)\right)\right)^{-} d F_{1}\left(s_{1}\right) d F\left(y_{(1)}\right)^{n-1} .
$$

The sum of Equation (10) and (11) is equal to zero by definition of $\psi$. Hence, we can conclude that our entrant does not have strict incentives to deviate upwards in the first stage.

We follow a similar approach for downward deviations in the first stage, $p<b\left(s_{i}\right)$ :

(a) If $\hat{v}\left(s_{1}\right)>b\left(y_{(1)}\right)$ (i.e. $\left.s_{1}>\psi\left(y_{(1)}\right)\right)$, our entrant can be top bidder only with the incumbent and thus pays $\hat{v}\left(s_{1}\right)$ if he wins. In this case, bidding $p$ or $b\left(s_{i}\right)$ changes whether the deviating entrant wins only if $b\left(y_{(1)}\right) \in\left(p, b\left(s_{i}\right)\right)$ and $s_{1}<\phi\left(s_{i}\right)$. If either $b\left(y_{(1)}\right)>b\left(s_{i}\right)$ or $s_{1}>\phi\left(s_{i}\right)$ our entrant loses with both $p$ and $b(s)$ because either he is outbid in the first stage by another entrant or in the second stage by the incumbent, respectively. If $b\left(y_{(1)}\right)<p$ and $s_{1}<\phi\left(s_{i}\right)$ our entrant wins with both $p$ and $b\left(s_{i}\right)$. However, if $b\left(y_{(1)}\right) \in\left(p, b\left(s_{i}\right)\right)$ and $s_{1}<\phi\left(s_{i}\right)$, the bid $b\left(s_{i}\right)$ causes our entrant to be a top bidder in the first stage that outbids the incumbent in the second, whereas this is not the case when the entrant bids $p$ instead. Thus, the deviation decreases the expected payoffs in:

$$
\begin{aligned}
\int_{b^{-1}(p)}^{s_{i}} \int_{\psi\left(y_{(1)}\right)}^{\phi\left(s_{i}\right)}\left(v\left(s_{i}, s_{1}\right)-\hat{v}\left(s_{1}\right)\right) d F_{1} & \left(s_{1}\right) d F\left(y_{(1)}\right)^{n-1} \\
& \geq \int_{b^{-1}(p)}^{s_{i}} \int_{\psi\left(y_{(1)}\right)}^{\phi\left(y_{(1)}\right)}\left(v\left(s_{i}, s_{1}\right)-\hat{v}\left(s_{1}\right)\right) d F_{1}\left(s_{1}\right) d F\left(y_{(1)}\right)^{n-1} \\
& \geq \int_{b^{-1}(p)}^{s_{i}} \int_{\psi\left(y_{(1)}\right)}^{\phi\left(y_{(1)}\right)}\left(v\left(y_{(1)}, s_{1}\right)-\hat{v}\left(s_{1}\right)\right) d F_{1}\left(s_{1}\right) d F\left(y_{(1)}\right)^{n-1},
\end{aligned}
$$

where we have used the definition of $\phi$, first, and the monotonicity of $v$, second.

(b) If $\hat{v}\left(s_{1}\right)<b\left(y_{(1)}\right)$ (i.e. $s_{1} \leq \psi\left(y_{(1)}\right)$ ), our entrant can only be top bidder with type $y_{(1)}$ entrant and hence pays price $\max \left\{v\left(y_{(1)}, s_{1}\right), \hat{v}\left(\psi\left(y_{(1)}\right)\right)\right\}$ if he wins. In this case, bidding $p$ or $b\left(s_{i}\right)$ changes whether the deviating entrant wins only if $b\left(y_{(1)}\right) \in\left(p, b\left(s_{i}\right)\right)$. If $b\left(y_{(1)}\right)<p$ our entrant wins with both $b\left(s_{i}\right)$ and $p$ and if $b\left(y_{(1)}\right)>b\left(s_{i}\right)$ our entrant loses with both $b\left(s_{i}\right)$ and $p$, in both cases, as a consequence of Property P1. If $b\left(y_{(1)}\right) \in\left(p, b\left(s_{i}\right)\right)$, then $y_{(1)} \leq s_{i}$ and our entrant is the top bidder with highest bid if he bids $b\left(s_{i}\right)$ but he is not when he bids $p$. Property 
P1 implies that he wins with $b\left(s_{i}\right)$ and hence get payoffs $v\left(s_{i}, s_{1}\right)-\max \left\{v\left(y_{(1)}, s_{1}\right), \hat{v}\left(\psi\left(y_{(1)}\right)\right\}\right.$. However, the bid $p$ only wins if the deviating bidder is a top bidder and finds it profitable to outbid the other top bidder entrant, i.e. $v\left(s_{i}, s_{1}\right)-\max \left\{v\left(y_{(1)}, s_{1}\right), \hat{v}\left(\psi\left(y_{(1)}\right)\right)\right\} \geq 0$. Thus, the payoffs after the deviation are at most $\left(v\left(s_{i}, s_{1}\right)-\max \left\{v\left(y_{(1)}, s_{1}\right), \hat{v}\left(\psi\left(y_{(1)}\right)\right)\right\}\right)^{+}$. Consequently, the deviation decreases the expected payoffs at least in:

$$
\begin{aligned}
\left.\int_{\hat{b}^{-1}(p)}^{s_{i}} \int_{0}^{\psi\left(y_{(1)}\right)}\left(v\left(s_{i}, s_{1}\right)-\max \left\{v\left(y_{(1)}, s_{1}\right), \hat{v}\left(\psi\left(y_{(1)}\right)\right)\right\}\right)^{-} d F_{1}\left(s_{1}\right)\right) d F\left(y_{(1)}\right)^{n-1} \\
\left.\geq \int_{\hat{b}^{-1}(p)}^{s_{i}} \int_{0}^{\psi\left(y_{(1)}\right)}\left(v\left(y_{(1)}, s_{1}\right)-\max \left\{v\left(y_{(1)}, s_{1}\right), \hat{v}\left(\psi\left(y_{(1)}\right)\right)\right\}\right)^{-} d F_{1}\left(s_{1}\right)\right) d F\left(y_{(1)}\right)^{n-1} \\
\left.\quad=\int_{\hat{b}^{-1}(p)}^{s_{i}} \int_{0}^{\psi\left(y_{(1)}\right)}\left(v\left(y_{(1)}, s_{1}\right)-\hat{v}\left(\psi\left(y_{(1)}\right)\right)\right)^{-} d F_{1}\left(s_{1}\right)\right) d F\left(y_{(1)}\right)^{n-1} .
\end{aligned}
$$

To conclude why our entrant does not have strict incentives to deviate downwards, note that the sum of equations (14) and (17) is equal to zero by definition of $\psi$.

Finally, we conclude our argument with the following result.

Proposition 6. If all bidders play our proposed equilibrium, the second best allocation associated to $\phi$ is implemented.

Proof. Let $s_{(1)} \equiv \max \left\{s_{i}\right\}_{i \neq 1}$. If $\phi\left(s_{(1)}\right)>s_{1}$, the second best allocates the good to the entrant with the highest type. To see why our auction implements this outcome, note that the monotonicity of the entrant's first stage bid means that the entrant of type $s_{(1)}$ is a top bidder. The bid functions in the second stage mean that the entrant of type $s_{(1)}$ wins if the other top bidder is the incumbent, since $\phi\left(s_{(1)}\right)>s_{1}$. This entrant also wins when the other top bidder is another entrant because of Property P1. If $\phi\left(s_{(1)}\right)<s_{1}$, the second best allocates the good to the incumbent. To see why our auction implements this outcome, note that $\phi\left(s_{(1)}\right)<s_{1}$ implies that $\psi\left(s_{(1)}\right)<s_{1}$ and hence $b\left(s_{i}\right)<s_{1}$ and $\hat{v}\left(\phi\left(s_{(1)}\right)\right)<\hat{v}\left(s_{1}\right)$, i.e. the incumbent submits the highest bid in both stages, and hence wins the auction as required.

\section{Alternative Solutions to Rushes}

In this section, we discuss three alternative solutions to the multi-stage format that we have proposed. We focus on mechanisms that use an initial ascending phase because we want to understand whether our negative message regarding the use of open ascending formats is robust the use of some natural 
variant of the format introduced in section 4. All natural alternatives we could consider suffer severe limitations. First of all, we have assumed in our description of the open ascending auction a standard random tie breaking rule in case of a tie. A natural question is whether the open ascending auction could be amended with an efficient tie breaking rule. The fact that bidders know ex-ante that, in case of a tie, an efficient tie breaking rule is adopted does not avoid the occurrence of rushes. Suppose in fact that an efficient tie breaking rule is in place and that this rule prevents the occurrence of rushes. Then the argument by contradiction employed in the proof of Proposition 1 can be used to show that the resulting allocation cannot be implemented because a profitable deviation exists. Thus, the main difference between our proposed solution and those alternatives that use as a base the standard open ascending auction (as the first two proposals below) is that the multi-stage auction avoids the occurrence of rushes, while any open ascending auction can, at best, resolve them ex-post. Solving rushes ex-post is not as effective as avoiding them. The reason is that it is harder to deal well with the fact that, at the price at which the rush occurs, even the highest entrant would be better off losing the auction. How to select such highest type to be the winner in an incentive compatible way? We see two possibilities.

The first proposal for an efficient tie breaking rule is to decrease the price from the one at which the exit of the incumbent caused the rush to a lower one, and then proceed with a second ascending phase. The idea behind such solution is to select the entrant with the highest type by making sure that in equilibrium the final price determined by the second ascending phase is lower than the valuation of the entrant who wins. That is, this solution ensures that the efficient tie braking rule is incentive compatible by guaranteeing that there is no ex-post regret for the winner. The obvious drawback is that the final price must be lower than the one at which the incumbent exited the first ascending phase, which requires to discriminate against the incumbent, which we do not find realistic in practice. For this reason, while we conjecture that it is possible to fill in the details of the rules, so that this type of solution could work, we do not analyze it formally. Moreover, those details will involve setting a starting price for the second ascending phase that requires fine knowledge of the ex-ante distributions of bidders' types. ${ }^{31}$

The second proposal is to take the price at which the rush occurred as binding. Since the entrant with the highest type is the one that suffers the least from ex-post regret, if allocated the asset at the

\footnotetext{
${ }^{31}$ The price cannot be decreased back to zero, as it would not be compatible with the entrants dropping from the auction according to some increasing bidding function in the first ascending phase: any entrant would have a profitable deviation to stay active till a rush occurs, and to participate to the second ascending phase.
} 
binding price, a natural way to proceed is to have entrants compete for the right not to be allocated the object at the binding price. The loser of this competition (and thus the winner of the object) is necessarily the entrant with highest type. We investigate this second option more formally below because we find it more appealing than the first one. A drawback of this mechanism is that bidders who do not get the asset have to pay.

Suppose a modified open ascending auction, in which bidders that tie participate in the following auxiliary auction. Each bidder submits a (non-negative) sealed bid, the one submitting the lowest bid gets the good and pays the current price of the open ascending auction. The other bidders do not get the good, but have to pay the lowest bid in the auxiliary auction. In case of a tie, the object is allocated according to the uniformly random tie breaking rule. This auxiliary auction can indeed be interpreted as a Vickrey auction, in which the $m$ bidders that tie bid for the right to lose in the tie breaking rule. In general, a bidder whose value is privately known to be equal to $V$ and that has tied with others at a price $p$ finds it optimal to bid $(p-V)^{+}$. The argument is the standard one for second price auction with private values. ${ }^{32}$ Under this tie-breaking rule, it is still weakly dominant for the incumbent to stay in the auction until the price reaches her value and bid zero in the tie breaking auction. After the incumbent quits, entrants can infer the incumbent's value and therefore, in case of a tie, the previous argument pins down their optimal bid in the tie breaking auction. The entrants' optimal play in the open ascending auction after either the other entrant or the incumbent quits is as in the case of the standard tie breaking rule. Finally, the entrant's equilibrium bid behavior in information sets in which no bidder has quit must be described. We propose a bid function constructed as in Section 4.1, just replacing Equation (5) by the following equation:

$\beta \int_{\gamma\left(s_{i}\right)}^{1}\left(v\left(s_{i}, s_{1}\right)-\hat{v}\left(s_{1}\right)\right) \frac{d F_{1}\left(s_{1}\right)}{1-F_{1}\left(\gamma\left(s_{i}\right)\right)}-(1-\beta) \frac{1}{1-F\left(s_{i}\right)} \int_{s_{i}}^{\rho\left(\gamma\left(s_{i}\right)\right)}\left(v\left(\tilde{s}, \gamma\left(s_{i}\right)\right)-\hat{v}\left(\gamma\left(s_{i}\right)\right)\right) d F(\tilde{s})=0$,

where $\beta$ is defined as in Equation (5), and in which entrants bid in the second price auction that solves the ties as described above. The proof that entrants do not have incentives to deviate from this bid function is the same as the proof of Proposition 2. It is straightforward to check that this equilibrium implements the second best.

The two proposals described so far use as a building block the standard open ascending price

\footnotetext{
${ }^{32}$ To see why there is no other bid that does better, we shall argue that this bid lets the bidder get the object, and hence gives payoffs $V-p$ whenever it is more profitable than paying the minimum bid (in the auxiliary auction) of the other bidders, say $\tilde{b}$. In the case $V-p<0$, this is because bidding $(p-V)^{+}$means winning if and only if $(V-p)>-\tilde{b}$, whereas in the case $V-p>0$, bidding 0 maximizes the chances of winning which is preferable to losing in any case.
} 
auction, which leads to rushes because it allows all active entrants to react at the same time to potential negative information that can be aggregated when observing the exit of the incumbent. This suggests a third alternative proposal that uses a modified ascending format, which is not standard, as it limits the information available to bidders. By restring the access to available information this mechanism avoids rushes, and implements the (second best) efficient allocation as our multi-stage sealed bid format. As a matter of fact, the two mechanisms share also the same equilibrium analysis.

We propose the following variation to the open ascending auction we described in section 4 . This is also a dynamic game in which bidders decide when to quit. The price starts from zero, and increases continuously until one entrant quits. Then, the price stops increasing and the following algorithm is implemented until only one entrant is active. The identify of the entrants that last quit is made public. The bidders that have not quit yet can decide (independently and simultaneously) whether to quit. If some other entrants quit, we repeat the former algorithm. Otherwise, the price begins to increase continuously again until some other entrant quits. In this case, we repeat the former algorithm. At the end of algorithm, the auctioneer reveals whether the incumbent is still active, or not, and, if not, at which price she exited the auction. In the former case, the ascending auction is restarted at the price at which the penultimate entrant exited, and the remaining entrant competes against the incumbent under the standard rules of the open format. In the latter case, the penultimate entrant to exit is readmitted, and the ascending auction is restarted at the price at which the penultimate entrant exited. The two remaining entrants compete under the standard rules of the open format. In case both simultaneously exit at the start of the new ascending phase, the winner is the entrant who was still active at the end of the first ascending phase.

These rules imply that the equilibrium price at which an entrant exits in the first ascending phase is the same as the first round bid in the multi-stage sealed bid format. Further, the equilibrium prices at which the two remaining active bidders quit in the second ascending phase are the same as the second round bids in the multi-stage sealed bid format. The second part follows from the first part holding true, and the fact that an open ascending auction is strategically equivalent to a second price auction, when there are only two bidders. To see why the first part is true, notice that the only extra information that the modified open auction offers to an entrant in the first ascending phase compared to the first stage bidding of the multi-stage auction, is the drop out prices of the other entrants. However, such information is irrelevant in order to determine the highest price at which is profitable to be active in the first ascending phase. The condition that determines such price is equation (8) 
from section 6 , and, in fact, the same interpretation for this break even condition holds here.

The proposed modified ascending auction works because it conceals information about the bidding from the incumbent. The obvious drawback compared to the multi-stage auction is that it discriminates against entrants by not allowing them to observe the incumbent's behavior.

We find the fact that these rules can implement the second best instructive as it clarifies that the reason behind the failure of the standard open ascending auction to implement the second best is due to the release of all available information publicly and as it becomes available.

\section{Closing Remarks and Conclusions}

In this paper, we have studied a realistic setting for privatizations in which open ascending auctions do not perform well in terms of efficiency. We have shown that a two-stage auction used in reality, e.g. ENI, Telebras not only dominates the open ascending auction, but also maximizes the total expected social surplus.

The key element of our two-stage auction is that bidders submit binding offers in an initial round and the two bidders submitting the highest bids are allowed to raise their offers. This is also a reasonable model of how bargaining is conducted in some environments in which trade is not organized through a formal auction, as it is sometimes the case of takeovers. Consequently, our analysis also applies to these cases.

The novel source of inefficiencies of the open ascending auction that we point out is due to rushes. We have provided a relatively general, yet tractable, model that fits the applications mentioned above well. It further illustrates that is impossible for ascending formats to implement the (second best) efficient allocation under standard tie breaking rules. The study of the second best under a fully general specification would allow, for instance, coverage of applications where there are multiple incumbents. We think that in most applications of interest there is typically one main incumbent and, as a consequence, our model should capture the key source of inefficiencies, and our proposed solution will approximate the (second best) efficient one. That said, we expect that, in a general environment, a multi-stage variation of the mechanism proposed here will implement the (second best) efficient allocation.

More generally, we think that our model points out a relevant drawback of open ascending formats that is inherent in their nature of providing all new available information publicly and as it becomes available. Thus, our results suggest that the use of these mechanisms is not ideal when some market 
participants have a superior information that affects the valuations of the other market participants. This contrasts with the standard view that open formats are desirable when information aggregation is an important issue. We hope that our work will stimulate further research in the design of mechanisms that optimally regulate the amount of information released to the market.

One implication of rushes that we have not fully explored, which could be seen as an extension of the current model for future research, is that rushes preclude information aggregation. As we pointed out, this is so as, after a rush occurs, bidders with different private information share the same optimal action, which implies that the detailed information they carry is not aggregated. In our model this does not matter, as the entrants' private information does not affect the valuations of the other entrants, nor that of the incumbent. In general, and independently of the implications for efficiency, one might argue that is desirable for the market price to incorporate this detailed information, so that the market price can reflect the fundamental value behind it. A further implication is that rushes would matter with a higher frequency that our model suggests, because they would be detrimental even if they involved a subset of the active bidders, and if they did not affect the final allocation.

Finally, our model analyses a single unit framework. While the analysis of a multi-unit market model is beyond the scope of this paper, we expect that our primary insights will carry over to more complex environments. In particular, the effect that we point out suggests that the volatility of markets, pointed out in a private value set up by Bulow and Klemperer (1994) will exacerbate in a setting with private and common components, and in which some market participants have superior information. 


\section{References}

Amir, R. (2005): "Supermodularity and Complementarity in Economics: An Elementary Survey," Southern Economic Journal, 71(3), 636 - 660.

Birulin, O., And S. Izmalkov (2011): "On Efficiency of the English Auction," Journal of Economic Theory, 146(4), 1398-1417.

Boone, J., And J. K. Goeree (2009): "Optimal Privatizations using Qualifying Auctions," The Economic Journal, 119, 277-297.

Bulow, J., And P. Klemperer (1994): "Rational Frenzies and Crashes," Journal of Political Economy, 102(1), 1-23.

Caffarelli, F. V. (1998): "The ENI group Multiple Round Auction Procedure," Rivista Di Politica Economica, 88(12), 109-140.

Chung, K.-S., And J. C. Ely (2002): "Ex-Post Incentive Compatible Mechanism Design,” mimeo, Northwestern University.

Coddington, E. A. E., And N. Levinson (1984): Theory of Ordinary Differential Equations. Krieger Publishing Company, first edn.

Dubra, J., F. Echenique, And A. M. Manelli (2009): "English auctions and the StolperSamuelson theorem," Journal of Economic Theory, 144(2), 825-849.

Dutra, J., And F. Menezes (2002): "Hybrid Auctions," Economics Letters, 77(3), 301-307.

Hernando-Veciana, A., and F. Michelucci (2011): "Second Best Efficiency and The English Auction," Games and Economic Behavior, 73(2), 496-506.

(2013): "On the Optimality of Not Allocating," mimeo.

Holmström, B., and R. Myerson (1983): "Efficient and Durable Decision Rules with Incomplete Information," Econometrica, 51, 1799-1820.

Klemperer, P. (1998): "Auctions with Almost Common Value: The "Wallet Game" and its Applications," European Economic Review, 42, 757-769. 
(2002): "What really matters in Auction Design," Journal of Economic Perspectives, 16(1), 169-189.

Krishna, V. (2002): Auction Theory. Academic Press, first edn.

— (2003): “Asymmetric English Auctions," Journal of Economic Theory, 112, 261-288.

Levin, D., And L. Ye (2008): "Hybrid Auctions Revisited," Economics Letters, 99(3), 591-594.

Maskin, E. (1992): "Auctions and Privatization," in Privatization: Symposium in honour of Herbert Giersh, ed. by H. Siebert. Institute fur Weltwirtshaft an der Univarsitat Kiel.

Milgrom, P., And R. Weber (1982): "A Theory of Auctions and Competitive Bidding," Econometrica, 50, 1089-1122.

Myerson, R. B. (1981): "Optimal Auction Design," Mathematics of Operation Research, 6(1), 58-73.

Nigerian-Communications-Commission (2007): "Information Memorandum 800MHz Spectrum Auction," Discussion paper, Nigerian Communications Commission, http://www.ncc.gov.ng/ index .php?option=com_docman\&task=doc_download\&gid=165\&Itemid=.

Perry, M., E. Wolfstetter, and S. Zamir (2000): "A Sealed Bid Auction that matches the English Auction," Games and Economic Behavior, 33(2), 265-273.

Vickrey, W. (1961): “Counterspeculation, Auctions, and Competitive Sealed Tenders," Journal of Finance, 16, 8-37.

YE, L. (2007): "Indicative bidding and a theory of two-stage auctions," Games and Economic Behavior, 58, 181-207. 


\section{Working Paper Series}

ISSN 1211-3298

Registration No. (Ministry of Culture): E 19443

Individual researchers, as well as the on-line and printed versions of the CERGE-EI Working Papers (including their dissemination) were supported from institutional support RVO 67985998 from Economics Institute of the ASCR, v. v. i.

Specific research support and/or other grants the researchers/publications benefited from are acknowledged at the beginning of the Paper.

(c) Ángel Hernando-Veciana and Fabio Michelucci, 2013

All rights reserved. No part of this publication may be reproduced, stored in a retrieval system or transmitted in any form or by any means, electronic, mechanical or photocopying, recording, or otherwise without the prior permission of the publisher.

Published by

Charles University in Prague, Center for Economic Research and Graduate Education (CERGE) and

Economics Institute of the ASCR, v. v. i. (EI)

CERGE-El, Politických vězňů 7, 11121 Prague 1, tel.: +420 224005 153, Czech Republic.

Printed by CERGE-EI, Prague

Subscription: CERGE-EI homepage: http://www.cerge-ei.cz

Phone: + 420224005153

Email: office@cerge-ei.cz

Web: http://www.cerge-ei.cz

Editor: Michal Kejak

The paper is available online at http://www.cerge-ei.cz/publications/working_papers/.

ISBN 978-80-7343-293-5 (Univerzita Karlova. Centrum pro ekonomický výzkum a doktorské studium)

ISBN 978-80-7344-285-9 (Národohospodářský ústav AV ČR, v. v. i.) 
CERGE-EI

P.O.BOX 882

Politických vězňů 7

11121 Praha 1

Czech Republic http://www.cerge-ei.cz 